\title{
HASTANE YERİ SEÇIMINNDE NESNEL AĞIRLIKLANDIRMALI SEZGİSEL BULANIK VIKOR YÖNTEMİ
}

\author{
Sait GÜL $1^{1^{*}}$ \\ 1Bahçeşehir Üniversitesi Mühendislik ve Doğa Bilimleri Fakültesi İşletme Mühendisliği Bölümü, İstanbul \\ ORCID No: http://orcid.org/0000-0002-6011-0848
}

\begin{tabular}{|c|c|}
\hline Anahtar Kelimeler & Öz \\
\hline $\begin{array}{l}\text { Sezgisel bulanık sayılar, VIKOR, } \\
\text { OWA, Hastane yeri seçimi. }\end{array}$ & 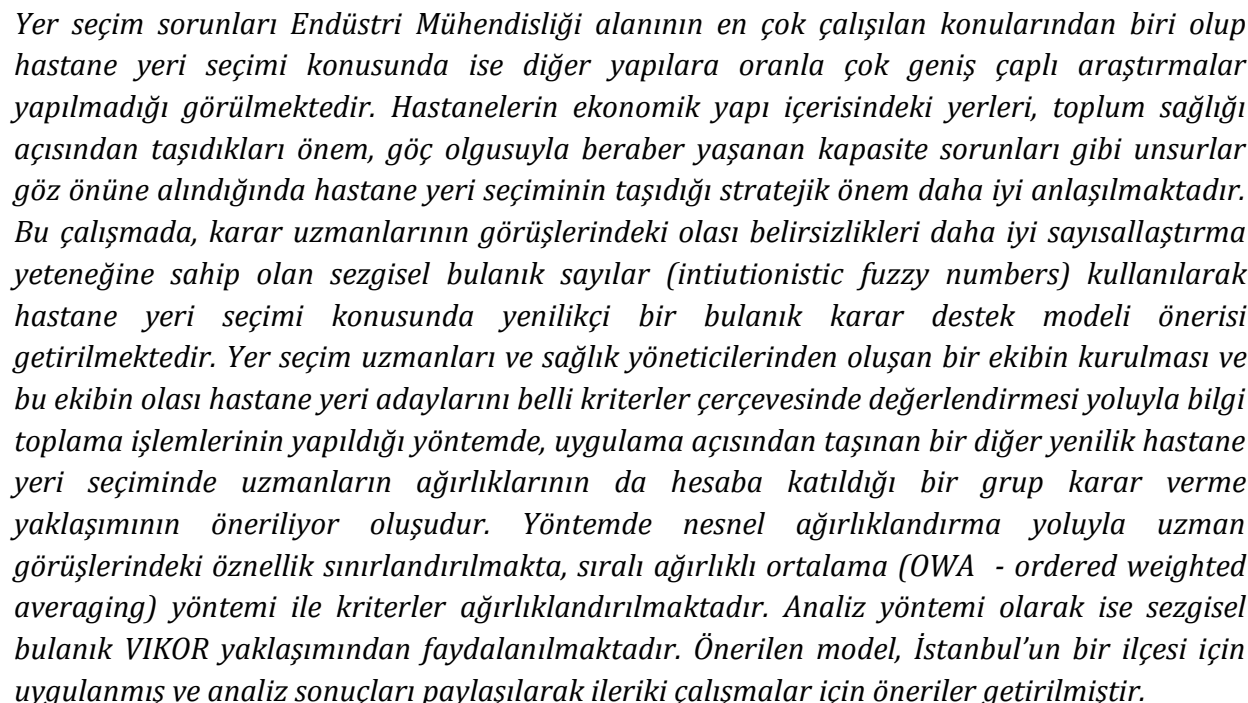 \\
\hline
\end{tabular}

\section{INTUITIONISTIC FUZZY VIKOR METHOD WITH OBJECTIVE WEIGHTING FOR HOSPITAL} SITE SELECTION

\begin{tabular}{ll}
\hline Keywords & Abstract \\
\hline Intuitionistic fuzzy numbers, & Location selection problem is among the most studied research fields of industrial engineering \\
VIKOR, OWA, Hospital site & area but studies on hospital site selection are relatively scarce in the literature. Hospital \\
selection. & location analysis carries critical and strategic importance, especially when considering their \\
meaning in economic structure, public health management, or in terms of inadequate \\
capacity problems arising from immigration phenomenon, etc. In this study, a fuzzy multiple \\
attribute decision-making model is proposed. As an application novelty, the model utilizes \\
intuitionistic fuzzy numbers because they have a better capability in the quantification of \\
vagueness in experts' opinions. In the model, data are gathered from decision experts who \\
have different experience levels represented by expertise weights in location analysis and \\
health management. Experts evaluate site alternatives by utilizing linguistic terms. An \\
objective weighting approach is chosen as the last application novelty for determining the \\
importance of criteria with the aim of reducing natural subjectivity embedded in expert \\
evaluations. There are two fundamental methods in the model; OWA (ordered weighted \\
averaging) is chosen for objective weighting of attributes and the intuitionistic fuzzy VIKOR \\
method is utilized for analysis of the alternatives. The application is performed in a district of \\
Istanbul and the analysis results and future research suggestions are shared.
\end{tabular}

*Sorumlu yazar; e-posta : $\underline{\text { sait.gul@eng.bau.edu.tr }}$ 


\section{Giriş}

Yer seçim sorunlarının akademik olarak incelenmesi Weber (1909)'e kadar gitmekte olup Endüstri Mühendisliği alanının en temel ve karmaşık sorunlarından biri olarak dikkat çekmektedir. Köken itibariyle bu konudaki çalışmalar çoğunlukla fabrika yeri seçimine odaklanmışlardır (Kuo, Lu, Tzeng, Lin ve Huang, 2013; Rikalovic, Cosic ve Lazarevic, 2014; Liu, Lin, Hsieh ve Tzeng, 2018 gibi). Ancak günümüzde, ekonomik gelişmelerin ve küreselleşmenin yarattığı etkiyle birlikte endüstri mühendisleri sadece üretim işletmeleriyle ilgili sorunları çözmekle yetinmemekte, hizmet işletmelerinin sorunlarına da mühendislik yaklaşımlarıyla çözüm getirebilmektedirler.

Yer seçim, karar vericiler açısından stratejik bir önem taşır çünkü bu sorunların çözümü pek çok ilişkili sonuç yaratabilmektedir. Araştırmaların temel çıktısı, doğal olarak coğrafi bir konum olmakta ve verilen karar, seçilen yerdeki doğal koşullar üzerinde ister istemez olumsuz etkide bulunma potansiyeli taşımaktadır. Özellikle, hastane gibi kimyasal ve tehlikeli atık çıkarma riski taşıyan tesisler için yer seçimi yapılırken oldukça dikkatli olunmalı, doğaya en az zararı verecek şekilde yer seçiminin yapılmasına çalışılmalıdır.

Diğer kritik bir nokta da yer seçim kararının ekonomik boyutudur. Bu karara göre yapılacak yatırımlara ilişkin maliyetler oldukça yüksek boyutlardadır. Hastanenin genişleme olanakları, ulaşımın kolaylığı, coğrafik yapının uygunluğu, doktor ve hemşire gibi asal personelin temin edilebilmesi gibi pek çok etken dikkate alındığında yer seçim sorunlarının taktik bir sorundan çok stratejik bir nitelik taşıdığı anlaşılmaktadır (Soltani ve Marandi, 2011). Bunların yanı sıra, hastaneler, günümüzde ekonomik hayatta yer alan işletmeler olarak değerlendirildiklerinden dolayı karşımıza rekabet konusu da çıkmaktadır (Wu, Lin ve Chen, 2007).

Sosyolojik bir kavram olan göç olgusunun etkisiyle kentlerdeki nüfus artmakta, nüfus arttıkça etkinliği düşen hizmet kollarının en önemlilerinden biri sağlık sektörü olmaktadır. Hastanelerin ya da hastanelerdeki yatak ve doktor sayılarının yetersizliği önemli bir sorun oluşturabilmektedir (Kim, Senaratna, Ruza, Kam ve Ng, 2015). Bu açıdan, talebe yetişebilmek ve herkesin sağlık hizmeti alabilmesini sağlamak amacıyla yeni hastanelerin kurulması gerekmektedir.
Bu çalışmada, yukarıda açıklanan gerekçelere bağlı olarak bir hastane yeri seçim modeli önerisi sunulmakta ve model, İstanbul'un bir ilçesi için uygulanmaktadır. Önerilen modelde, sezgisel bulanık VIKOR yöntemi kullanılmaktadır. Karar vericilerin görüşlerinin dilsel terimlerle ifade edilmelerinin ardından bu ifadelerdeki belirsizliğin daha etkin bir şekilde modellenebilmesi açısından sezgisel bulanık sayıların kullanımı tercih edilmiştir. Karar verme yöntemlerinde uzmanlardan alınan kriter bazlı değerlendirmelerin bir araya getirilmesinde kriter ağırlıklarına gereksinim duyulmaktadır. Bir sonraki bölümde açıklandığı gibi yazındaki çalışmaların tümü öznel ağırlıklandırma yöntemlerinden yararlanmaktadırlar. Öznellik, yani manipülasyon riskini azaltma amaciyla, önerilen modelde nesnel ağırlıklandırma tercih edilmektedir.

Yapılan çalışma ile yazına, hastane yeri seçimi uygulaması açısından üç önemli noktada katkı sunulduğunu söylemek mümkündür. İlk olarak, sezgisel bulanık sayıların kullanılması ile bulanık mantıktaki üyelik derecelerinin ifade edemediği üye olmama dereceleri de karar sürecine dâhil edilmiș, bu yolla kararlardaki belirsizliğin daha iyi temsil edilmesi sağlanmıştır. İkinci yenilik, grup kararının verilmesinde uzmanların ağırlıklarının göz önüne alınması ile hastane yeri seçimine özgü bir grup karar verme yönteminin önerilmesidir. Üçüncü nokta ise öznellikten kaynaklanan sorunların giderilmesi amacıyla nesnel ağırlıklandırma yönteminin tercih edilmesi ve daha önce bu karar sorununda kullanımı bulunmayan OWA yönteminin uygulama olanaklarının araştırılmasıdır.

Çalışmanın genel mimarisi şu şekildedir: 2. bölümde hastane yeri seçimine ilişkin yazın özeti sunulmakta ve tartışılmakta; 3 . bölüm çalışmada önerilen çok kriterli karar verme modelinin ayrıntılarını içermekte; 4. bölümde önerilen modelin uygulanmasına ilişkin açıklamalar getirilerek eniyi hastane yeri seçimi önerisi yapılmakta; 5. ve son bölümde ise yönteme ilişkin sonuçlar verilerek gelecek çalışma önerileri açıklanmaktadır.

\section{Yazın Taraması}

Yazında hastane yeri seçimiyle ilgili yapılan çalışmalara ilişkin özet bilgiler Ek 1'de verilen tabloda özetlenmektedir.

Yazın taraması neticesinde ulaşılabilen29 çalışmanın 26'sı akademik makalelerden oluşmaktadır. Çalışmaların büyük çoğunluğu Analitik Hiyerarşi Süreci (AHS)'den 
yararlanmaktadır. AHS yönteminin temel mantığı karar sürecinin uzmanın görüș ve beklentileri doğrultusunda çözümlenmesidir. AHS'yi klasik anlamda kullanan 11 çalışma (Stern, Mehrez, Tal ve Shemuel, 1995; Wu ve diğ., 2007; Aydın, Öznehir ve Akçall, 2009; Chatterjee ve Mukherjee, 2013; Chiu ve Tsai, 2013; Dehe ve Bamford, 2015; Ahmed, Mahmoud ve Aly, 2016; Dell'Ovo, Capolongo ve Oppio, 2018; Ajaj, Shareef, Jasim, Hasan, Noori ve Hassan, 2019; Soltani, Inaloo, Rezaei, Shaer ve Riyabi, 2019; Sahin, Ocak ve Top, 2019) bulunmakta olup bulanık AHS'den yararlanan çalışma sayısı ise 3 'tür (Vahidnia, Alesheikh ve Alimohammadi, 2009; Aydın, 2009; Soltani ve Marandi, 2011). Özetle eldeki 26 çalışmadan 14'ü AHS'den yararlanmaktadır. AHS ve bulanık AHS kullanan çalıșmaların 8'i AHS'yi bașka yöntemlerle destekleyerek bütünleșik olarak kullanmışlardır. Stern ve diğ. (1995), 0-1 tamsayılı programlama ile AHS'yi; Vahidnia ve diğ. (2009), Soltani ve Marandi (2011),Ahmed ve diğ. (2016), Dell'Ovo ve diğ. (2018), Ajaj ve diğ. (2019) ile Soltani ve diğ. (2019) Coğrafi Bilgi Sistemleri (CBS) ile bulanık ya da klasik AHS'yi birlikte kullanmışlardır. Dehe ve Bamford (2015) ise AHS ile kanıtsal muhakeme (evidential reasoning) yöntemlerini karşılaştırmaktadır.

AHS ve bulanık AHS dışında yöntem önerisi getiren makaleler de bulunmaktadır. Wissem, Ahmed ve Mounir (2011) Fas'ın Sfax kenti için hastane yeri seçimi yaptıkları çalışmalarında hedef programlama yöntemini kullanmaktadırlar. Kim ve diğ. (2015), CBS ile kanıt temelli (evidence-based) muhakeme yöntemini birlikte kullanarak ABD'nin Teksas eyaletinde yeni açılacak bir hastanenin yerini belirlemeye çalıșmaktadırlar. Senvar, Otay ve Bolturk (2016), İstanbul kenti için bir bulanık TOPSIS yöntemi kullanmaktadır ve yazında ilk kez hastane yeri seçiminde tereddütlü bulanık sayllar (hesitant fuzzy numbers) kullanılmış olmaktadır. Sen (2017), gri sayllar temelli ARAS (ARAS-G; Additive Ratio Assessment Method with grey numbers) yöntemini üç uzmanlı bir grup karar verme yaklaşımı çerçevesinde hastane yeri seçim problemi için önermektedir. Çelikbilek (2018), Türkiye'deki bir hastane yeri için bulanık VIKOR yönteminden yararlanmakta ve grup kararının verilmesinde hastane yöneticilerinin görüşlerini bütünleştirmektedir. Adalı ve Tuş (2019), yazında ilk kez nesnel ağırlıklandırma yöntemlerinden biri olan CRITIC ile TOPSIS, EDAS ve CODAS mesafe tabanlı çok kriterli karar verme yöntemlerini birlikte kullanmakta ve sonuçlarını karşılaştırmaktadır. Çalışmaya göre üç yöntem de aynı sıralamaları sunmaktadır.

Kullanılan yöntemler özetle ele alınacak olursa çalışmaların biri hariç (Adalı ve Tuş, 2019) tümünde karar vericilerin öznel değerlendirmelerinin dikkate alındığı görülmektedir. $\mathrm{Bu}$ değerlendirmeler alternatiflerin puanlanmasında belki bir zorunluluk durumundadır çünkü çoğu zaman kriterlerin nesnel olarak ölçümlenebilmeleri olanaksız ya da çok zordur. Bununla birlikte kriterlerin öznel olarak önceliklendirilmeleri, özellikle hastane yeri seçimi gibi büyük yatırım gerektiren durumlarda eleștiri konusudur (Yu ve Lai, 2011). Kriter ağırlıklandırırken nesnellik sağlanması, verilecek kararların daha güvenilir olmasını sağlayabilecektir (Wang ve Parkan, 2005). Bu açıdan, bu çalışmada nesnel kriter ağırlıklandırmadan yararlanılmıştır.

Yazında bulunan 29 çalışmanın 26'sı akademik makalelerden oluşmakta olup kalan üçü daha önce yer seçimi çalışması yapılan üç hastaneye ilişkin raporlardır. Soltani ve Marandi (2011) tarafindan aktarlan Saskatoon (2010), Virginia (2009) ve Queensland (2008) hastanelerine ilişkin raporlardan yer seçim kriterleri konusunda yararlanılmıştır. 26 akademik çalışmanın sadece 2 'si herhangi bir yer seçim yöntemi önermemekte olup yer seçim kriterlerinin belirlenmesi açısından önemli olarak değerlendirilmișlerdir (Jordan, Roderick, Martin ve Barnett, 2004; Gibson, Martin ve Singer, 2004). Ek 1'deki tablo incelenerek ve en fazla atıf yapılan kriterler alt kırılımları (altkriterler) da ilgili makalelerden seçilerek çalışmada kullanılacak olan kriter havuzu oluşturulmuştur (Şekil 2).

\section{3. Önerilen Çok Kriterli Bulanık Karar Verme Yöntemi}

$\mathrm{Bu}$ çalışmada, hastane yeri seçimiyle ilgili bir sezgisel bulanık çok kriterli karar verme modeli önerilmektedir. Bulanık mantığın karar sorunlarının çözümündeki belirsizliği daha iyi temsil etme yeteneği olduğundan dolayı bu çalışmada bulanıklaștırma tercih edilmiștir. Keza, Vahidnia ve diğ. (2009), karar sorunlarının çözümünde ortaya çıkan belirsizliğin ve kesinsizliğin yarattığ karmaşayla baş edebilmek için bulanık mantığın iyi bir yol olduğunu belirtmektedirler. Önerilen model Şekil 1'de özetlenmektedir. 


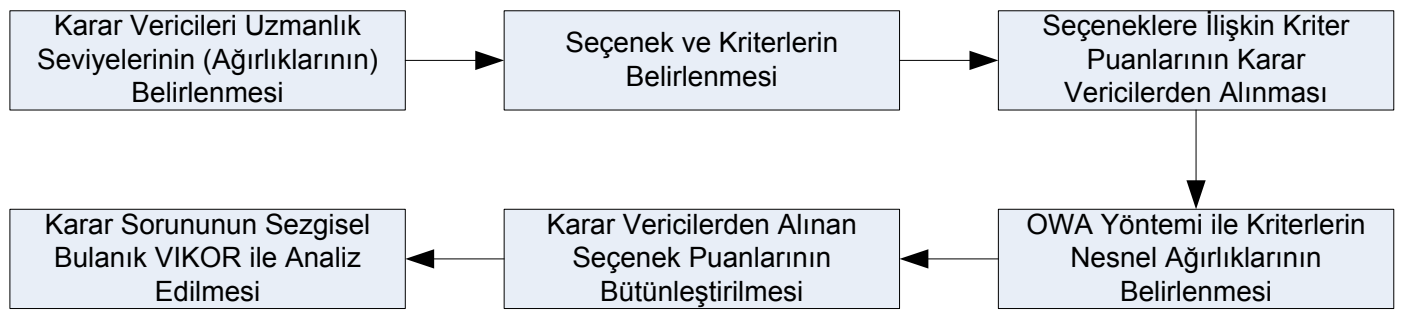

Şekil 1. Önerilen Karar Verme Yönteminin Adımları

\subsection{Sezgisel Bulanık Sayılar}

Zadeh (1965), grup kararlarının verilmesinde sistemsel öznellik, insan yargısının kesinsizliği (değiş̧ebilirliği), karar vericilerin değerlendirmelerindeki dilsel ifade kullanım zorunluluğu gibi nedenlerden dolayı bulanık sayıların karar verme süreçlerinde oldukça yararlı olduğunu belirtmektedir. Bulanık mantık, küme kuramının genel bir hali olup bir elemanın herhangi bir kümeye belli bir üyelik derecesi ile üye olması

$\mathrm{A}=\left\{<z, \mu_{A}(z), \vartheta_{A}(z)>\mid z \in Z\right\}$

Bu denklemde $\mu_{A}(z)$ ile z'nin $\mathrm{Z}$ kümesine üye olma derecesi gösterilmekte, $\vartheta_{A}(z)$ ise $\mathrm{z}$ elemanının $\mathrm{Z}$ kümesine üye olmama derecesini göstermektedir. Burada bulunan $0 \leq \mu_{A}(z)+\vartheta_{A}(z) \leq 1$ koşulu, bu iki üyelik derecesinin toplamının 1 'den küçük olabilmesine olanak tanımaktadır. Buna göre, belirsizliğin bir derecesi (sezgisel indeks) var demektir: $\quad \pi_{A}(z)=1-\mu_{A}(z)-\vartheta_{A}(z) \quad$ (Gupta, Mehlawat ve Grover, 2016).

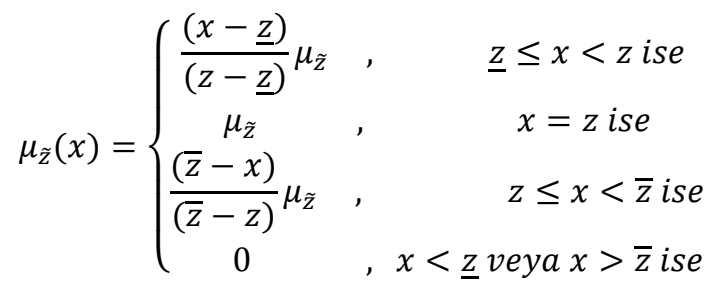

$\vartheta_{\tilde{z}}(x)=\left\{\begin{array}{cc}\frac{\left(z-x+\vartheta_{\tilde{z}}(x-\underline{z})\right)}{(z-\underline{z})}, & \underline{z} \leq x<z \text { ise } \\ \vartheta_{\tilde{z}}, & x=z \text { ise } \\ \frac{\left(x-z+\vartheta_{\tilde{z}}(\bar{z}-x)\right)}{(\bar{z}-z)}, & z \leq x<\bar{z} \text { ise } \\ 0 \quad, & x<\underline{z} \text { veya } x>\bar{z} \text { ise }\end{array}\right.$

Wu, Zhang, Xu ve Li (2018), alt ve üst limitleri sırasıyla kötümser ve iyimser değerler olarak anlamında kullanılmaktadır. Atanassov (1986) tarafından ortaya atılan sezgisel bulanık kümeler (intuitionistic fuzzy sets) ise bir elemanın bir kümeye üyeliğini iki parametre ile ölçmektedir: üyelik derecesi ve üye olmama derecesi. Bu iki parametreli temsilin yararı, karar vericinin kararsızlığının da modellenebiliyor olmasıdır. Z'de tanımlı A sezgisel bulanık kümesi Denklem (1) ile gösterilebilir.

Bu çalışmada, üçgen sezgisel bulanık sayılar tercih edilmektedir ( $\mathrm{Li}, 2010)$. Üçgen bulanık sayı $\tilde{z}=$ $\left((\underline{z}, z, \bar{z}) ; \mu_{\tilde{z}}, \vartheta_{\tilde{z}}\right)$ ile gösterilmekte olup $z$ sezgisel bulanık sayısı üç parametre ve iki üyelik derecesi ile temsil edilmektedir. "Yaklaşık $z$ " dilsel ifadesine denk gelecek şekilde belirlenen bulanık $z$ sayısı, $\underline{Z}$ ile $\bar{z}$ arasında bir değerdir. Üye olma ve üye olmama dereceleri ise sirasiyla Denklem (2) ve (3) kullanılarak hesaplanabilmektedir $(\mathrm{Wu}, \mathrm{Zhang}, \mathrm{Xu}$ ve $\mathrm{Li}, 2018$ ).

isimlendirmektedir. Denklem (2)'deki $\mu_{\tilde{z}}$ değeri, en olası üyelik derecesi ve Denklem (3)'deki $\vartheta_{\tilde{z}}$ ise, en 
olası üye olmama derecelerini göstermektedir. Li (2010), sezgisel bulanık sayılarla yapılacak işlemlerin aşağıdaki gibi olacağını göstermektedir.

$$
\begin{aligned}
& \tilde{z}+\tilde{a}=\left((\underline{z}+\underline{a}, z+a, \bar{z}+\bar{a}) ; \mu_{\tilde{z}} \wedge \mu_{\tilde{a}}, \vartheta_{\tilde{z}} \vee \vartheta_{\tilde{a}}\right) \\
& \tilde{z} \tilde{a}=\left((\underline{z a}, z a, \bar{z} \bar{a}) ; \mu_{\tilde{z}} \wedge \mu_{\tilde{a}}, \vartheta_{\tilde{z}} \vee \vartheta_{\tilde{a}}\right) ; \tilde{z}>0 \text { ve } \tilde{a}>0 \text { ise, } \\
& \tilde{z} \tilde{a}=\left((\underline{z} \bar{a}, z a, \bar{z} \underline{a}) ; \mu_{\tilde{z}} \wedge \mu_{\tilde{a}}, \vartheta_{\tilde{z}} \vee \vartheta_{\tilde{a}}\right) ; \tilde{z}<0 \text { ve } \tilde{a}>0 \text { ise, } \\
& \tilde{z} \tilde{a}=\left((\overline{z a}, z a, \underline{z a}) ; \mu_{\tilde{z}} \wedge \mu_{\tilde{a}}, \vartheta_{\tilde{z}} \vee \vartheta_{\tilde{a}}\right) ; \tilde{z}<0 \text { ve } \tilde{a}<0 \text { ise, } \\
& \lambda \tilde{z}=\left((\lambda \underline{z}, \lambda z, \lambda \bar{z}) ; \mu_{\tilde{z}}, \vartheta_{\tilde{z}}\right) ; \lambda>0 \text { ise, } \\
& \lambda \tilde{z}=\left((\lambda \bar{z}, \lambda z, \lambda \underline{z}) ; \mu_{\tilde{z}}, \vartheta_{\tilde{z}}\right) ; \lambda<0 \text { ise, }
\end{aligned}
$$

Denklem (10) ile verilen Hamming mesafesi, çok kriterli karar vermede puanlar ile ideal noktalar $\tilde{z}=\left((\underline{z}, z, \bar{z}) ; \mu_{\tilde{z}}, \vartheta_{\tilde{z}}\right) \quad$ ve $\quad \tilde{a}=\left((\underline{a}, a, \bar{a}) ; \mu_{\tilde{a}}, \vartheta_{\tilde{a}}\right) \quad$ iki sezgisel bulanık sayı ve $\lambda$, bir gerçel sayı olsun.

arasındaki uzaklıkların hesaplanmasında kullanılmaktadır (Wu ve diğ., 2018).

$d(\tilde{z}, \tilde{a})=\frac{1}{3}[|\underline{z}-\underline{a}|+|z-a|+|\bar{z}-\bar{a}|]+\max \left(\left|\mu_{\tilde{z}}-\mu_{\tilde{a}}\right|,\left|\vartheta_{\tilde{z}}-\vartheta_{\tilde{a}}\right|\right)$

\section{2 Önerilen Yöntem}

\subsubsection{Adım 1: Karar Vericilerin ve Uzmanlık Seviyelerinin Belirlenmesi}

Hastane yeri seçimi ile ilgili olarak şehir planlamacıları, kamu yöneticileri, hastane yöneticileri ve danışmanlardan kurulu bir ekip olușturulması ve bu uzmanlardan hastane yeri seçimi konusunda yardım alınması gerekmektedir. Her uzmanın farklı tecrübe seviyelerinde bulunmaları olası olup uzmanlık seviyelerinin belirlenmesinde uzmanların ortaklașa değerlendirme yapmaları, yani grup içerisinde yapacakları bir değerlendirme ile grup üyelerini puanlamaları istenmektedir. Koksalmis ve Kabak (2019) da grup karar verme sorunlarındaki uzman görüşlerinin karara yansitılmasında hangi nesnel yolların kullanılabileceğine ilişkin olarak yazını taramışlar ve bu yöntemlerin bir sınıflandırmasını sunmuşlardır. İlgili makalede de belirtildiği gibi nesnel ağırlıklandırma yaklaşımlarından çoğunlukla elde uzman ağırlığı yokken ya da soruna özgü olarak öznel ağırlıkların kullanılması istenmiyorken yararlanılmaktadır. Yöntemin bu adımında öznel uzman ağırlıklandırma uygulama kolaylığı açısından tercih edilmekte olup bu amaçla kullanılacak ölçek Tablo 1'de verilmektedir. (Zhang, Zhang, Li, Liu ve Yang, 2017). Bunun haricindeki nesnel ya da öznel yöntemlerin kullanılması da tercih edilebilir.
Tablo 1

Karar vericilerin uzmanlık seviyelerine ilişkin dilsel terimler (Zhang ve diğ, 2017)

\begin{tabular}{cc}
\hline Uzmanlı Derecesi & Sezgisellik Dereceleri \\
\hline Tam Uzman (TU) & $(0,90 ; 0,10)$ \\
Uzman (U) & $(0,75 ; 0,20)$ \\
Az Uzman (AU) & $(0,50 ; 0,45)$ \\
Emin Değil (ED) & $(0,35 ; 0,60)$ \\
\hline
\end{tabular}

Tablonun ikinci sütunundaki değerler $\left(\mu_{k}, \vartheta_{k}\right)^{\prime}$ dir. Uzmanlık kümesine olan üyelikler uzmanlık seviyesi düştükçe azalmakta, ancak üye olmama dereceleri artmaktadır. Zhang ve diğ. (2017), uzmanlık seviyelerinin dikkate alınması ile $\mathrm{k}$ adet uzmanın ağırlıklarının $\quad\left(\lambda_{k}\right)$ Denklem (11) ile hesaplanabileceğini göstermiştir. Burada, $\pi_{k}$ sezgisel indekstir.

$\lambda_{k}=\frac{\mu_{k}+\pi_{k}\left(\mu_{k} /\left(\mu_{k}+\vartheta_{k}\right)\right)}{\sum_{k}\left(\mu_{k}+\pi_{k}\left(\mu_{k} /\left(\mu_{k}+\vartheta_{k}\right)\right)\right)}$ 


\subsubsection{Adım 2: Seçeneklerin ve Kriterlerin Belirlenmesi}

Olası hastane yeri adaylarının belirlenmesi üst merciler ve karar organları tarafindan yapılabileceği gibi karar ekibi tarafından da bir takım ön eleme özellikleri dikkate alınarak belirlenebilir. Kriterlerin belirlenmesi ise yazın taramasının sonuçlarına ve uzmanların görüşlerine dayanmaktadır. Çalıșmada, $m$ adet hastane yeri alternatifini $i$ indisi ile $(i=1, \ldots, m)$ ve değerlendirmede kullanılacak $n$ adet kriteri ise $j$ indisi ile gösterelim $(j=1, \ldots, n)$.

\subsubsection{Adım 3: Seçeneklerin Karar Vericilerce Değerlendirilmeleri}

Seçenekler ve kriterler belirlendikten sonra seçeneklerin kriter bazlı olarak değerlendirilmesi gerekmektedir. Burada, her karar verici her alternatifi her kriter açısından dilsel terimler kullanarak değerlendirir. Modelde $\mathrm{Wu}$ ve diğ. (2018) tarafından önerilen dilsel terim kümesi kullanılmaktadır (Tablo 2).

Tablo 2

Seçeneklerin Puanlandırılmasındaki Dilsel Terimler (Wu ve diğ., 2018)

\begin{tabular}{lll}
\hline Dilsel Terim & Kısaltma & Sezgisel Bulanık Sayı \\
\hline Çok Kötü & ÇK & $((0,0,1) ; 0,7 ; 0,2)$ \\
Kötü & K & $((0,1,3) ; 0,8 ; 0,1)$ \\
Orta Kötü & OK & $((1,3,5) ; 0,9 ; 0)$ \\
Orta & O & $((3,5,7) ; 1 ; 0)$ \\
Orta İyi & OI & $((5,7,9) ; 0,9 ; 0)$ \\
İyi & I & $((7,9,10) ; 0,8 ; 0,1)$ \\
Çok İyi & ÇI & $((9,10,10) ; 0,7 ; 0,2)$ \\
\hline
\end{tabular}

\subsubsection{Adım 4: Kriter Ağırlıklarının Hesaplanması}

Bugüne kadarki tüm hastane yeri seçimi çalışmalarında kriter ağırlıkları uzman görüşüne dayalı olarak belirlenmiștir. Uzman görüșlerinin doğasındaki öznelliğin yaratacağ riskini bertaraf etmek için modelde nesnel ağırlıklandırma kullanılmaktadır. Nesnel ağırıklandırma yapılan çalışmalarda uzmanlardan kriterlerin önemleri konusunda herhangi bir bilgi talep edilmez. Yazında pek çok nesnel ağırlıklandırma yöntemi bulunmaktadır (Barukab, Abdullah, Ashraf, Arif ve Khan, 2019; Liu ve Liu, 2019; Arya ve Kumar, 2020; Kaaffah, Ridwan ve Novitasari, 2020; Wu, Liao, Hu, Lin, Zhou, Zhang ve $\mathrm{Xu}, 2020$ ). Yu ve Lai (2011), kriterlerdeki puanların birbirlerinden olan uzaklıklarına göre ağırlıkların belirlenmesi konusundaki yöntemleri özetlemektedir. Yazında bu yaklașıma dair bazı eleștiriler bulunmakta olup bunların en önemlilerinden biri, mesafe tabanlı bu anlayışın ağırlık belirlemede güvenilmez olduğudur (Han ve Xiao, 2009). Benzer eleştiriler göz önüne alındığında nesnel ağırlıklandırmanın klasik yöntemleri yerine OWA (ordered weighted averaging - sıralı ağırlıklı ortalama) tercih edilmiştir (Yager, 1988).

OWA yaklaşımının genel öğesi, kriterlerin önemleri değil, sırasallıklarının önemleridir. Bir karar sorununda kriter puanları şu eşitlik ile bütünleştirilir: $\quad F\left(a_{1}, \ldots, a_{n}\right)=\sum_{j=1}^{n} w_{j} b_{j}$. Burada OWA yöntemini farklılaștıran unsur $i$ indisine ilișkin olup alternatifin büyüklüğünü değil büyüklügünün sırasını temsil etmesidir (O'Hagan, 1988). Yani $b_{j}$, $\left(a_{1}, a_{2}, \ldots, a_{n}\right)$ alternatifler kümesinin $j$ 'nci büyük elemanidır $\left(b_{1}>b_{2}>\ldots>b_{n}\right)$.

OWA çalışmalarının öncülerinden biri O'Hagan (1988)'a ait olup çalışmada veyalık derecesi (orness degree) tanımı yapılmaktadır. Sırasal ağırlıkların toplamı 1 olmak üzere, eğer $[1,0, \ldots, 0]$ gibi bir ağırlık vektörü söz konusuysa enbüyük puan sonuç olarak kabul edilmiș; eğer $[0,0, \ldots, 1]$ gibi bir vektör söz konusuysa enküçük değer sonuç olarak alınmış olmaktadır. İlk ağırlık vektörü enbüyüklemeyi sağladığı için bulanık mantıktaki "veya (or)" operatörüne; ikinci vektör enküçüklemeyi sağladığı için "ve (and)" operatörüne karşllık gelmektedir. Böylece tüm vektör elemanlarının 0 ile 1 arasındaki değişiminde veyalık derecesi ortaya çıkmaktadır.

Yager (1988), Fuller ve Majlender (2003) ve Wang ve Parkan (2005) gibi yazarlar eniyileme temelli olarak OWA yaklaşımları önermişlerdir. Önerilen modelde Ruan, Kabak ve Quinones (2013) tarafından geliştirilen OWA yaklaşımından yararlanılmaktadır çünkü orada işlemsel kolaylık açısından daha etkin olan bir yöntem söz konusudur. Bunun için ardışık kriter ağırlıklarının bir $\beta$ parametresiyle oransal bileşimi kullanılmakta ve Denklem (12) ile verilen veyalık derecesine bağlı bir ilişki tanımlanmaktadır. 
$w_{j}=\beta * w_{j-1} \quad ; \quad w_{1}= \begin{cases}\frac{1-\beta}{1-\beta^{n}}, & \beta \neq 1 \\ \frac{1}{n}, & \beta=1\end{cases}$

$\mathrm{Bu}$ yönteme göre, veyallk derecesi 0'a yaklaştırıldıkça yüksek puanlara; 1'e yaklaştırıldıkça düşük puanlara daha yüksek ağırlık verilmiş olur. Denklem (12), $\beta \neq 1$ durumu için Denklem (13)'deki ağırlık belirleme formülüne

$w_{j}=\frac{1-\beta}{1-\beta^{n}} \beta^{j-1}, \beta>0, \beta \neq 1$

$\operatorname{veyallk}(w)=\frac{1-\beta}{(n-1) *\left(1-\beta^{n}\right)} \sum_{j=1}^{n}(n-j) \beta^{j-1}, \quad \beta>0, \quad \beta \neq 1$

değerlendirmeleri ise $\tilde{x}_{i j k}$ ile gösterilsin. Son terim, $k$ uzmanının $i$ alternatifini $j$ kriteri açısından değerlendirdiği dilsel terimi ifade etmektedir. Bütünleşik sonucu gösteren dilsel terim Denklem (15) ile belirlenmektedir.

Bu adımda çok kriterli karar verme yöntemlerinin temel aracı olan karar matrisi oluşturulmaktadır. $k$ adet karar verici $m$ adet alternatif hastane yerini $n$ dönüştürülebilmektedir. Buradaki veyalık derecesi Denklem (14)'de verilmekte olup bu denklemden istenen bir veyalık derecesi için $\beta$ parametresi çekilerek Denklem (13)'deki yerine konulursa OWA ağırlıkları kolayca belirlenebilir. adet kritere göre dilsel terimlerle

değerlendirmişlerdir. Uzmanların ağırlıkları $\lambda_{k}$ ile,

$\tilde{x}_{i j}=\sum_{k} \lambda_{k} \tilde{x}_{i j k}=\left(\left(\underline{x}_{i j}, x_{i j}, \bar{x}_{i j}\right) ; \mu_{\tilde{x}_{i j}}, \vartheta_{\tilde{x}_{i j}}\right), i=1, \ldots, m, j=1, \ldots, n$

\subsubsection{Adım 6: Sezgisel Bulanık VIKOR Yöntemi ile Hastane Yeri Seçimi}

Son yıllarda çok kriterli karar verme yöntemleri yazında artan bir hızla kullanılmaktadır. VIKOR da bu alanda en fazla atıf alan yöntemlerin başında gelmekte olup açılımı Sırpça "VIsekriterijumskaoptimizacija i KOmpromisno Resenje" şeklindedir (Opricovic, 1998). Türkçe karşılığı "Çok Kriterli Optimizasyon ve Uzlaşık Çözüm yöntemi" olan VIKOR, çatışan kriterlerin varlığı durumunda alternatifleri, pozitif ideal bir çözüme yakınlık ve negatif ideal bir çözümden uzaklık verilerini bütünleşik bir şekilde ele alarak sıralar ve uzlaşık bir çözüm sunar (Opricovic ve Tzeng, 2004).

VIKOR yöntemi ile enbüyük grup faydası ve enküçük bireysel pişmanlık sağlanacak șekilde karar verilmeye çalışmaktadır. Bu yöntemde her alternatif, kriterler açısından değerlendirilir ve ideal çözüme göreli yakınlık derecesine göre alternatifler sıralanır (Kaya ve Kahraman, 2011). Yazında klasik VIKOR yöntemini bulanık ortamda ele alan çalışmalar da bulunmaktadır (Opricovic, 2011; Liao ve $\mathrm{Xu}, 2013$; Gupta ve diğ., 2016). Burada üçgen sezgisel bulanık sayılarla uyumlu bir VIKOR yöntemine gereksinim duyulduğu için $\mathrm{Wu}$ ve diğ. (2018) tarafından önerilen yöntem tercih edilmekte olup yöntemde 7 adım bulunmaktadır. 
Adım 6.1. Adım 5 'te oluşturulan $\tilde{x}_{i j}$ karar matrisi Denklem (16) kullanılarak normalize edilir ve $\tilde{r}_{i j}$ matrisi oluşturulur. Normalize matriste $\mu_{\tilde{x}_{i j}}=\mu_{\tilde{r}_{i j}}$ ve $\vartheta_{\tilde{x}_{i j}}=\vartheta_{\tilde{r}_{i j}}$ olmak üzere $\quad \tilde{r}_{i j}=$ $\left(\underline{r}_{i j}, r_{i j}, \bar{r}_{i j}\right)=\left\{\begin{array}{l}\left(\frac{\underline{x}_{i j}}{\bar{x}_{\text {maxj }}}, \frac{x_{i j}}{\bar{x}_{\text {maxj }}}, \frac{\bar{x}_{i j}}{\bar{x}_{\text {maxj }}}\right), j \text { fayda tipi bir kriter ise } \\ \left(\frac{\underline{x}_{\text {minj }}}{\bar{x}_{i j}}, \frac{x_{\text {minj }}}{x_{i j}}, \frac{\underline{x}_{\text {minj }}}{\underline{x}_{i j}}\right), j \text { maliyet tipi bir kriter ise }\end{array}\right.$

Adım 6.2. Tüm kriterler bazında pozitif ve negatif ideal seçenekler oluşturulmalıdır. Denklem (17)'de verilen bulanık pozitif ve Denklem (18)'de verilen $\left(\left(\underline{r}_{i j}, r_{i j}, \bar{r}_{i j}\right) ; \mu_{\tilde{r}_{i j}}, \vartheta_{\tilde{r}_{i j}}\right) \quad$ değerleri bulunmaktadır. Denklem (16)'da $\bar{x}_{\text {maxj }}=\max \left\{\bar{x}_{i j} \mid i=1, \ldots, m\right\}$ ve $\underline{x}_{\text {minj }}=\min \left\{\underline{x}_{i j} \mid i=1, \ldots, m\right\}$ 'dir. bulanık negatif ideal seçenekler tüm alternatifler için birer karșılaștırma noktası olarak kullanılmaktadır.

$\tilde{f}_{j}^{*}=\left\{\begin{array}{l}\max _{i} \tilde{r}_{i j}=\left(\left(\max _{i} \underline{r}_{i j}, \max _{i} r_{i j}, \max _{i} \bar{r}_{i j}\right) ; 1,0\right), j \text { fayda tipi bir kriter ise } \\ \min _{i} \tilde{r}_{i j}=\left(\left(\min _{i} \underline{r}_{i j}, \min _{i} r_{i j}, \min _{i} \bar{r}_{i j}\right) ; 0,1\right), j \text { maliyet tipi bir kriter ise }\end{array}\right.$

$\tilde{f}_{j}^{-}= \begin{cases}\min _{i} \tilde{r}_{i j}=\left(\left(\min _{i} \underline{r}_{i j}, \min _{i} r_{i j}, \min _{i} \bar{r}_{i j}\right) ; 0,1\right), \quad j \text { fayda tipi bir kriter ise } \\ \max _{i} \tilde{r}_{i j}=\left(\left(\max _{i} \underline{r}_{i j}, \max _{i} r_{i j}, \max _{i} \bar{r}_{i j}\right) ; 1,0\right), \quad j \text { maliyet tipi bir kriter ise }\end{cases}$

Adım 6.3. VIKOR yönteminin temelindeki uzaklık ölçümü Denklem (19)'da verilmektedir. Bu, Denklem (10) ile verilen Hamming mesafesidir.

$d_{i j}=\frac{d\left(\tilde{f}_{j}^{*}, \tilde{r}_{i j}\right)}{d\left(\tilde{f}_{j}^{*}, \tilde{f}_{j}^{-}\right)}$

Adım 6.4. VIKOR yönteminde alternatifler değerlendirilirken $S_{i}$ grup faydası ve $R_{i}$ bireysel

$S_{i}=\sum_{j=1}^{n} w_{j} d_{i j}, i=1, \ldots, m$

$R_{i}=\max _{j} w_{j} d_{i j}, i=1, \ldots, m$

Adım 6.5. Her alternatif için $S_{i}$ ve $R_{i}$ değerlerinin bütünleştirilmesinden oluşan $Q_{i}$ indeksi hesaplanmalıdır. Denklem (22) ile verilen $Q_{i}$ indeksinde $S^{*}=\min _{i} S_{i}, S^{-}=\max _{i} S_{i}, R^{*}=\min _{i} R_{i}$ ve $R^{-}=\max _{i} R_{i}$ olup $v$ ise, stratejik bir katsayıdır ve $Q_{i}=v \frac{S_{i}-S^{*}}{S^{-}-S^{*}}+(1-v) \frac{R_{i}-R^{*}}{R^{-}-R^{*}}, i=1, \ldots, m$

Adım 6.6. Tüm alternatifler, $S_{i}, R_{i}$ ve $Q_{i}$ değerleri açısından ayrı ayrı artan sırada listelenir. Böylelikle üç adet sıralama bulunmuş olur. Bu sıralamalarda en düşük değerlere sahip alternatifler eniyi tercih konumundadırlar.
Böyle bir mesafe ölçümü, üçgen sezgisel bulanık sayı durumundaki değerlerin durulaştırılmasını (defuzzification) da sağlamaktadır.

pişmanlık değerlerinin her alternatif için hesaplanması gerekmektedir (Denklem 20 ve 21).

grup faydasının enbüyüklenmesine mi yoksa bireysel pişmanlığın enküçüklenmesine mi önem verildiğini ölçer. [0,1] aralığında bir değer olup genelde çalışmalarda 0,5 olarak alınmaktadır.

Adım 6.7. Aşağıdaki iki koşulun sağlanması durumunda $Q_{i}$ değerlerine göre yapılan sıralamada eniyi durumda olan seçenek hastane yeri tercih önerisi olarak sunulur. 
Koşul 1. Kabul edilebilir avantaj: Q'ye göre yapılan siralamada eniyi ilk iki alternatif $A^{(1)}$ ve $A^{(2)}$ olsun. $m$, toplam alternatif sayısı olmak üzere $Q\left(A^{(2)}\right)$ $Q\left(A^{(1)}\right) \geq 1 /(m-1)$ olmalıdır.

Koşul 2. Karar vermede kabul edilebilir istikrar: Qi'ye göre yapılan siralamada eniyi durumda olan $A^{(1)}$ alternatifi $S_{i}$ ve $R_{i}$ için yapılan sıralamalarda da eniyi olmalıdır.

Eğer yukarıdaki koşullardan ikisi de sağlanamıyor ise VIKOR yöntemi uzlaşı bir çözüm oluşturamamış demektir. Eğer koşullardan sadece biri sağlanamıyor ise aşağıdaki kurallara uygun olarak birden fazla alternatif içeren bir alternatifler kümesi önerilir.

(i) Eğer Koşul 1 sağlanamıyorsa, $Q\left(A^{(M)}\right)-Q\left(A^{(1)}\right)<1 /(m-1)$ koşulunu sağlayan ilk $M$ adet seçenek uzlaşık çözüm kümesidir: $\left\{A^{(1)}, A^{(2)}, \ldots, A^{(M)}\right\}$.

(ii) Eğer Koşul 2 sağlanamıyorsa, $A^{(1)}$ ve $A^{(2)}$ uzlaşı çözüm kümesinin elemanlarıdır.

\section{4. İstanbul'un Bir İlçesinde Hastane Yeri Belirleme Uygulaması}

Önerilen OWA temelli sezgisel bulanık VIKOR yöntemi İstanbul ilinin bir ilçesinde yeni kurulması düșünülen bir hastanenin yerinin belirlenmesi sürecinde destek bilgisi vermesi amacıyla 2019 yılı içerisinde uygulanmıştır. Belediye yöneticileriyle yapılan görüşmeler sırasında kendileri çeşitli ekonomik ve politik gerekçeler öne sürerek makale içerisinde belediyenin isminin geçmesini istememișlerdir. Yönteme ilișkin açıklamalar ilgili bölümlerde verilmekte olup veri gizliliği ilkelerine göre uzmanların kimlik bilgileri de saklı tutulmaktadır. Uzmanlarla yapılan görüșmelerde bilgi toplanması esnasında Araştırma ve Yayın Etiği ilkelerine özenle uyulmuştur. Ayrıca 2020 yılı öncesinde veri toplanmış olduğu için TR Dizin'in ilgili Etik ilkeleri uyarınca geriye dönük olarak Etik Kurul İznine gerek bulunmamaktadır.

\section{Adım 1: Karar Vericilerin ve Uzmanlık Seviyelerinin Belirlenmesi}

Bilgi ve uzmanlıklarına başvurulacak karar vericiler seçilerek, 4 kişilik bir takım oluşturulmuştur. Bu uzmanlardan ikisi hastane yeri ve operasyonları konusunda bilgi sahibi olan ve daha önce danışmanlık görevleri yürütmüş olan akademisyenler, biri bir devlet hastanesinde çalışan ve daha önce hastane genişletme projesinde uzmanlığına başvurulan bir hekim ve sonuncusu da kuruluşundan bu yana özel bir hastanenin yöneticiliğini yapmaktadır. Uzmanların uzmanlık seviyeleri ekip içerisinde belirlenmiş olup Tablo 3'ün ikinci satırında verilmektedir. Uzmanlık seviyelerinin karşılıkları olan sezgisellik dereceleri de bir sonraki satırda gösterilmektedir. Tablonun son satırında ise her uzmanın uzmanlık derecelerine göre hesaplanan ağırlıkları görülmektedir. U (uzman) değerlendirmesine sahip üçüncü karar verici için ağırlığın nasıl hesaplanacağı aşağıda örnek olarak verilmektedir.

$$
\begin{aligned}
\lambda_{4}=\frac{\mu_{4}+\pi_{4}\left({ }^{\mu_{4}} /\left(\mu_{4}+\vartheta_{4}\right)\right.}{\sum_{k}\left(\mu_{k}+\pi_{k}\left(\mu_{k} /\left(\mu_{k}+\vartheta_{k}\right)\right)\right)} \\
\quad=\frac{0,75+0,05(0,75 /(0,75+0,20))}{2 * 0,90+(0,50+0,05(0,50 /(0,50+0,45))+(0,75+0,05(0,75 /(0,75+0,20)))}=\frac{0,7895}{3,1158} \\
=0,2533
\end{aligned}
$$


Tablo 3

Uzmanlar ve Uzmanlık Seviyeleri

\begin{tabular}{ccccc}
\hline & Akademisyen-1 & Akademisyen-2 & Yönetici & Hekim \\
\hline Derece & TU & TU & U & AU \\
Sezgisellikleri & $(0,90 ; 0,10)$ & $(0,90 ; 0,10)$ & $(0,75 ;$ & $(0,50 ; 0,45)$ \\
& & & $0,20)$ & \\
Ağırlık & 0,2889 & 0,2889 & 0,2533 & 0,1689 \\
\hline
\end{tabular}

\section{Adım 2: Seçeneklerin ve Kriterlerin Belirlenmesi}

İstanbul'un incelenen ilçesinde üç adet devlet hastanesi bulunmakta olup kapasite yetersizliği nedeniyle yeni bir devlet hastanenin açılması gerektiği düşünülmektedir. İlk alternatif $(M)$, var olan merkezi hastaneden bağımsız olarak yine ilçe merkezinde daha geniş bir arazi üzerinde yeni bir hastane kurulması şeklindedir. İlçenin yeni kentleşen semtlerinden birine bir hastane kurulması ikinci alternatiftir (K), çünkü bu semt ilçe merkezine uzak olup özellikle acil servis hizmetleri konusunda dezavantajlı bir durum yaşamaktadır. Son alternatif $(\mathrm{F})$ ise, ilçenin diğer ilçelerde oturan vatandaşlara da kapılarını açması anlamında daha yüksek kapasiteli bir hastanenin kurulmasını içermekte olup bunun toplu taşıma ağlarına yakın bir lokasyonda bulunması düşünülmektedir. Buna göre, seçenekler şöyledir: $\mathrm{M}, \mathrm{K}$ ve $\mathrm{F}(i=1,2,3)$.

Hastanelerin değerlendirileceği kriterler de bu aşamada belirlenmektedir. Ek 1'de verilen yazın özeti tablosu ve uzman bilgileri göz önüne alınarak karar verici ekip tarafından bir kriter kümesi olușturulmuștur. Șekil 2'de özetlenen kriter kümesi 8 ana kriter içermektedir. Bunlardan beşinin alt kriterleri de bulunmakta olup toplam 21 kriter vardir $(j=1, \ldots, 21)$. Burada belirtilmesi gereken önemli bir varsayım, kriterler arasındaki olası ilişkilerin göz ardı edilmiş olmasıdır. Kriterlerin birbirlerinden bağımsız oldukları varsayılmıș olup bu da çalışmanın en önemli limitidir.
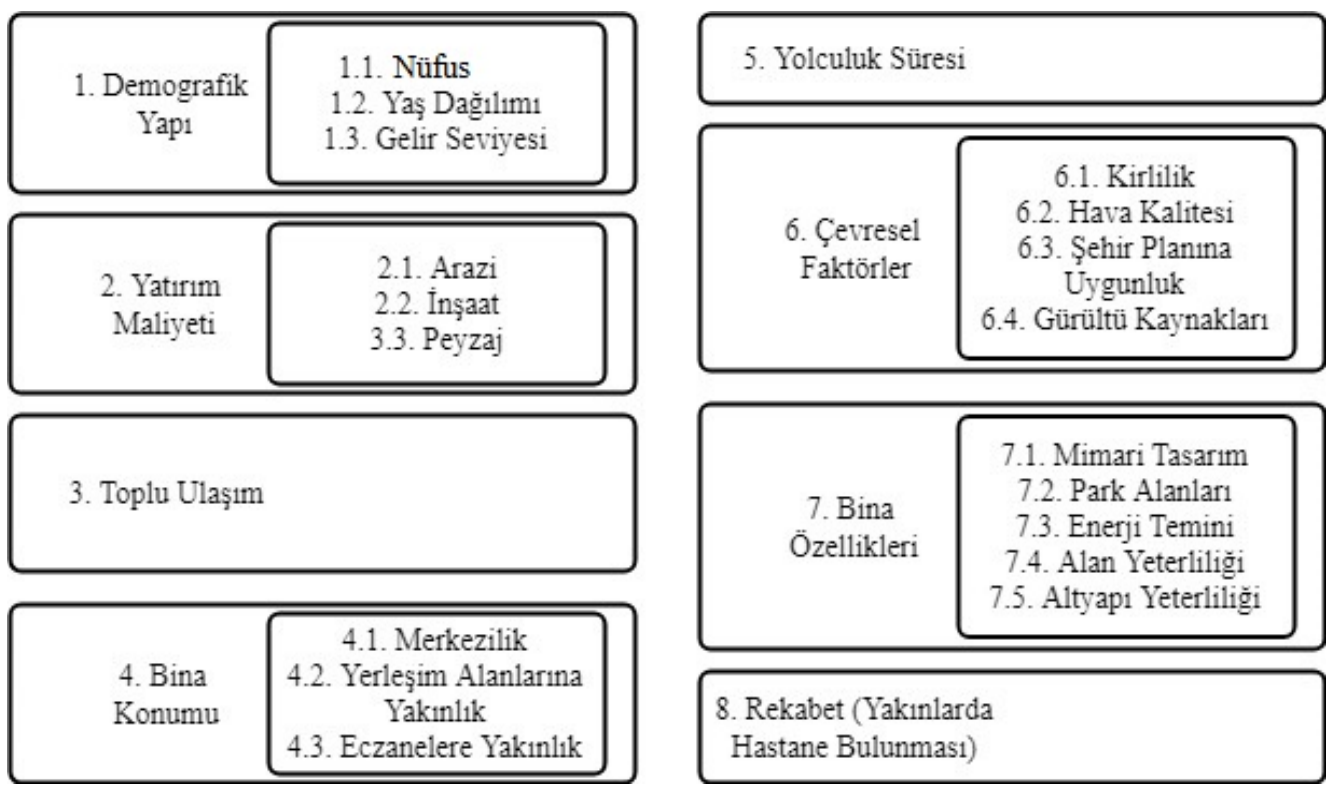

Şekil 2. Hastane Yeri Seçimi Kriter Kümesi 


\section{Adım 3: Seçeneklerin Karar Vericilerce Değerlendirilmesi}

Bir önceki adımda verilen üç aday hastane yeri, toplam 21 adet kriter temel alınarak 4 uzman tarafından ayrı ayrı değerlendirilmiştir. Tablo 2'deki dilsel terimler kullanılarak yapılan değerlendirmeler Tablo 4'de kriter bazlı olarak özetlenmektedir.

Tablo 4

Alternatiflerin Değerlendirilmesi

\begin{tabular}{|c|c|c|c|c|c|}
\hline & & $A-1$ & $A-2$ & $Y$ & $H$ \\
\hline \multirow{3}{*}{ Nüfus } & $\mathrm{K}$ & $\mathrm{OI}$ & $\mathrm{I}$ & $\mathrm{O}$ & $\mathrm{OK}$ \\
\hline & $\mathrm{O}$ & $\mathrm{I}$ & $\mathrm{OI}$ & OI & $\mathrm{I}$ \\
\hline & $\mathrm{M}$ & ÇI & $\mathrm{I}$ & $\mathrm{I}$ & $\mathrm{OI}$ \\
\hline \multirow{3}{*}{ Yaş Dağılımı } & $\mathrm{K}$ & $\mathrm{OI}$ & ÇI & OI & $\mathrm{O}$ \\
\hline & $\mathrm{O}$ & OI & $\mathrm{I}$ & $\mathrm{I}$ & $\mathrm{OI}$ \\
\hline & $\mathrm{M}$ & $\mathrm{O}$ & $\mathrm{K}$ & $\mathrm{O}$ & $\mathrm{O}$ \\
\hline \multirow{3}{*}{ Gelir Seviyesi } & $\mathrm{K}$ & $\mathrm{I}$ & ÇI & $\mathrm{I}$ & $\mathrm{I}$ \\
\hline & $\mathrm{O}$ & OI & $\mathrm{I}$ & $\mathrm{O}$ & $\mathrm{O}$ \\
\hline & $\mathrm{M}$ & OI & $\mathrm{OI}$ & OI & $\mathrm{I}$ \\
\hline \multirow{3}{*}{ Arazi Maliyeti } & $\mathrm{K}$ & $\mathrm{O}$ & $\mathrm{OI}$ & $\mathrm{O}$ & $\mathrm{K}$ \\
\hline & $\mathrm{O}$ & $\mathrm{OI}$ & $\mathrm{I}$ & ÇI & $\mathrm{OI}$ \\
\hline & M & $\mathrm{OK}$ & ÇK & ÇK & ÇK \\
\hline \multirow{3}{*}{ İnşaat Maliyeti } & $\mathrm{K}$ & $\mathrm{I}$ & ÇI & OI & $\mathrm{O}$ \\
\hline & $\mathrm{O}$ & $\mathrm{I}$ & I & $\mathrm{I}$ & $\mathrm{O}$ \\
\hline & M & $\mathrm{OK}$ & $\mathrm{O}$ & OI & $\mathrm{O}$ \\
\hline \multirow{3}{*}{ Peyzaj Maliyeti } & $\mathrm{K}$ & OI & $\mathrm{OI}$ & $\mathrm{O}$ & $\mathrm{OK}$ \\
\hline & $\mathrm{O}$ & $\mathrm{I}$ & $\mathrm{OI}$ & OI & $\mathrm{OI}$ \\
\hline & $\mathrm{M}$ & $\mathrm{O}$ & $\mathrm{I}$ & OI & $\mathrm{OI}$ \\
\hline \multirow{3}{*}{$\begin{array}{l}\text { Toplu } \\
\text { Ulaşım } \\
\text { İmkanı } \\
\end{array}$} & $\mathrm{K}$ & $\mathrm{OK}$ & $\mathrm{K}$ & $\mathrm{K}$ & ÇK \\
\hline & $\mathrm{O}$ & $\mathrm{OI}$ & $\mathrm{O}$ & $\mathrm{I}$ & ÇI \\
\hline & M & ÇI & ÇI & I & $\mathrm{OI}$ \\
\hline \multirow{3}{*}{ Merkezilik } & $\mathrm{K}$ & $\mathrm{K}$ & $\mathrm{O}$ & $\mathrm{O}$ & $\mathrm{K}$ \\
\hline & $\mathrm{O}$ & OI & $\mathrm{I}$ & ÇI & $\mathrm{I}$ \\
\hline & $\mathrm{M}$ & ÇI & I & $\mathrm{O}$ & $\mathrm{O}$ \\
\hline \multirow{3}{*}{$\begin{array}{c}\text { Yerleşim } \\
\text { Alanlarına } \\
\text { Yakınlik } \\
\end{array}$} & $\mathrm{K}$ & $\mathrm{O}$ & $\mathrm{O}$ & OK & $\mathrm{O}$ \\
\hline & $\mathrm{O}$ & $\mathrm{I}$ & $\mathrm{I}$ & ÇI & ÇI \\
\hline & $\mathrm{M}$ & ÇI & $\mathrm{I}$ & OI & $\mathrm{I}$ \\
\hline \multirow{3}{*}{$\begin{array}{l}\text { Eczanelere } \\
\text { Yakınlik }\end{array}$} & $\mathrm{K}$ & $\mathrm{OK}$ & OI & $\mathrm{O}$ & $\mathrm{O}$ \\
\hline & $\mathrm{O}$ & ÇI & I & $\mathrm{I}$ & $\mathrm{I}$ \\
\hline & $\mathrm{M}$ & ÇI & $\mathrm{I}$ & ÇI & ÇI \\
\hline \multirow{3}{*}{$\begin{array}{l}\text { Yolculuk } \\
\text { Süresi }\end{array}$} & $\mathrm{K}$ & $\mathrm{OK}$ & ÇK & $\mathrm{K}$ & ÇK \\
\hline & $\mathrm{O}$ & I & I & ÇI & I \\
\hline & $\mathrm{M}$ & ÇI & I & I & $\mathrm{OI}$ \\
\hline
\end{tabular}

\begin{tabular}{|c|c|c|c|c|c|}
\hline & & $A-1$ & $A-2$ & $Y$ & $H$ \\
\hline \multirow{3}{*}{ Kirlilik } & $\mathrm{K}$ & ÇI & ÇI & I & $\mathrm{O}$ \\
\hline & $\mathrm{O}$ & I & $\mathrm{O}$ & ÇI & OI \\
\hline & $\mathrm{M}$ & OI & $\mathrm{O}$ & I & OI \\
\hline \multirow{3}{*}{ Hava Kalitesi } & $\mathrm{K}$ & ÇI & ÇI & ÇI & ÇI \\
\hline & $\mathrm{O}$ & I & ÇI & I & $\mathrm{OI}$ \\
\hline & $\mathrm{M}$ & I & I & OI & OI \\
\hline \multirow{3}{*}{$\begin{array}{c}\text { Şehir Klanına } \\
\text { UyIunluk }\end{array}$} & $\mathrm{K}$ & ÇI & ÇI & I & ÇI \\
\hline & $\mathrm{O}$ & I & ÇI & OI & I \\
\hline & $\mathrm{M}$ & I & $\mathrm{OI}$ & OI & OI \\
\hline \multirow{3}{*}{$\begin{array}{c}\text { Gürülttü } \\
\text { Kaynakları }\end{array}$} & $\mathrm{K}$ & $\mathrm{I}$ & ÇI & $\mathrm{OI}$ & ÇI \\
\hline & $\mathrm{O}$ & $\mathrm{O}$ & $\mathrm{O}$ & I & $\mathrm{OK}$ \\
\hline & $\mathrm{M}$ & $\mathrm{OK}$ & ÇK & $\mathrm{K}$ & $\mathrm{OK}$ \\
\hline \multirow{3}{*}{ Mimari Tasarmm } & $\mathrm{K}$ & $\mathrm{O}$ & $\mathrm{OI}$ & OI & $\mathrm{O}$ \\
\hline & $\mathrm{O}$ & $\mathrm{O}$ & I & I & $\mathrm{O}$ \\
\hline & $\mathrm{M}$ & I & ÇI & $\mathrm{O}$ & $\mathrm{O}$ \\
\hline \multirow{3}{*}{ Park Alanları } & $\mathrm{K}$ & ÇI & ÇI & ÇI & ÇI \\
\hline & $\mathrm{O}$ & OI & $\mathrm{I}$ & $\mathrm{O}$ & $\mathrm{OK}$ \\
\hline & $M$ & $\mathrm{~K}$ & ÇK & $\mathrm{OK}$ & ÇK \\
\hline \multirow{3}{*}{ Enerji Temini } & $\mathrm{K}$ & OI & $\mathrm{OK}$ & $\mathrm{O}$ & I \\
\hline & $\mathrm{O}$ & I & I & I & ÇI \\
\hline & $M$ & ÇI & I & I & ÇI \\
\hline \multirow{3}{*}{$\begin{array}{c}\text { Alan } \\
\text { Yeterliliği }\end{array}$} & $\mathrm{K}$ & ÇI & ÇI & ÇI & ÇI \\
\hline & $\mathrm{O}$ & OI & $\mathrm{O}$ & $\mathrm{K}$ & $\mathrm{OK}$ \\
\hline & $\mathrm{M}$ & $\mathrm{K}$ & ÇK & $\mathrm{O}$ & ÇK \\
\hline \multirow{3}{*}{$\begin{array}{c}\text { Altyap1 } \\
\text { Yeterliliği }\end{array}$} & $\mathrm{K}$ & $\mathrm{O}$ & I & $\mathrm{O}$ & OI \\
\hline & $\mathrm{O}$ & $\mathrm{I}$ & ÇI & $\mathrm{I}$ & $\mathrm{I}$ \\
\hline & $\mathrm{M}$ & I & ÇI & OI & I \\
\hline \multirow{3}{*}{ Rekabet } & $\mathrm{K}$ & ÇI & ÇI & ÇI & ÇI \\
\hline & $\mathrm{O}$ & $\mathrm{K}$ & $\mathrm{OK}$ & $\mathrm{O}$ & $\mathrm{O}$ \\
\hline & $M$ & $\mathrm{O}$ & $\mathrm{I}$ & I & $\mathrm{OI}$ \\
\hline
\end{tabular}

\section{Adım 4: Kriter Ağırlıklarının Hesaplanması}

Çalışmada OWA yöntemi tercih edilmiş olup kriterlere ilişkin sırasal olarak azalan ya da artan bir ağırlık kümesi oluşturulmaktadır. Ağırlık kümelerinin elde edilebilmesi için öncelikle veyalı derecesinin belirlenmesi gerekmektedir. Duyarlılık analizi de yapılabilmesi açısından üç farklı veyalık derecesi için ağırlık kümeleri belirlenmiş̦tir: 0,25; 0,50; 0,75 (Tablo 5). Aşağıda 0,25 veyalık derecesi için yapılan hesaplamalar örnek olarak verilmektedir. 
$\operatorname{veyalık}(w)=0,25=\frac{1-\beta}{(21-1) *\left(1-\beta^{21}\right)} \sum_{j=1}^{21}(21-j) \beta^{j-1} \quad$ denklemi $\quad$ çözüldüğünde ağırlık kümesinin oluşturulmasında kullanılacak olan $\beta$ parametresi 1,1739 bulunmaktadır. Buna göre sırasal olarak ağırlıklar aşağıdaki şekilde hesaplanmaktadır.

$$
\begin{aligned}
& w_{1}=\frac{1-1,1739}{1-1,1739^{21}} 1,1739^{1-1}=0,0062 ; w_{2}=\frac{1-1,1739}{1-1,1739^{21}} 1,1739^{2-1}=0,0073 \\
& w_{3}=\frac{1-1,1739}{1-1,1739^{21}} 1,1739^{3-1}=0,0086 ; \ldots ; w_{21}=\frac{1-1,1739}{1-1,1739^{21}} 1,1739^{21-1}=0,1534
\end{aligned}
$$

0,50 veyalık derecesi için $\beta=1$ ve 0,75 için ise $\beta=0,8519$ olarak bulunmakta olup ilgili ağırlıklar Tablo 5'de verilmektedir.

Tablo 5

Farklı veyalık dereceleri için Ağırlık Kümeleri

\begin{tabular}{cccccccc}
\hline orness $=$ & 0,25 & 0,75 & 0,5 & orness $=$ & 0,25 & 0,75 & 0,5 \\
\hline 1 & 0,0062 & 0,1534 & 0,0476 & 12 & 0,0362 & 0,0263 & 0,0476 \\
2 & 0,0073 & 0,1307 & 0,0476 & 13 & 0,0425 & 0,0224 & 0,0476 \\
3 & 0,0086 & 0,1113 & 0,0476 & 14 & 0,0499 & 0,0191 & 0,0476 \\
4 & 0,0100 & 0,0948 & 0,0476 & 15 & 0,0586 & 0,0163 & 0,0476 \\
5 & 0,0118 & 0,0808 & 0,0476 & 16 & 0,0688 & 0,0138 & 0,0476 \\
6 & 0,0138 & 0,0688 & 0,0476 & 17 & 0,0808 & 0,0118 & 0,0476 \\
7 & 0,0163 & 0,0586 & 0,0476 & 18 & 0,0948 & 0,0100 & 0,0476 \\
8 & 0,0191 & 0,0499 & 0,0476 & 19 & 0,1113 & 0,0086 & 0,0476 \\
9 & 0,0224 & 0,0425 & 0,0476 & 20 & 0,1307 & 0,0073 & 0,0476 \\
10 & 0,0263 & 0,0362 & 0,0476 & 21 & 0,1534 & 0,0062 & 0,0476 \\
11 & 0,0309 & 0,0309 & 0,0476 & & & & \\
\hline
\end{tabular}

\section{Adım 5: Karar Matrisinin Oluşturulması}

$\mathrm{Bu}$ adımda alternatiflere ilişkin değerlendirmeler, uzmanların ağırlıkları kullanılarak bütünleştirilmekte ve VIKOR yönteminin uygulanmasına hazır olacak șekilde bir karar matrisinde toplanmaktadır. Tablo 4'te verilen değerlendirmeler Tablo 2'deki dilsel terim karşılıkları kullanılarak sezgisel bulanık sayılara dönüştürülmekte, daha sonra Denklem (15) kullanılarak dört farklı uzman görüşü tek bir bütünleşik görüşe indirgenmektedir. Örnek olarak Nüfus kriterinin $\mathrm{K}$ alternatifi için aldığ değerlendirmelerin bütünleştirilmesini ele alalım. Sirasıyla uzmanlardan OI-I-O-OK değerlendirmeleri alınmıştır. Denklem (8) ve (4)'e göre bütünleşik değerlendirme elde edilmektedir.

$$
\begin{aligned}
\tilde{x}_{11}=\sum_{k} \lambda_{k} \tilde{x}_{11 k} & =0,2889 *((5,7,9) ; 0,9 ; 0)+0,2889 *((7,9,10) ; 0,8 ; 0,1)+0,2533 *((3,5,7) ; 1,0)+0,1689 \\
& *((1,3,5) ; 0,9 ; 0)=((4,40 ; 6,40 ; 8,11) ; 0,8 ; 0,1)
\end{aligned}
$$

Tablo 6'da tüm alternatiflerin bütünleştirilmiş değerleri verilmektedir. Her bir alternatifin yanındaki ilk üç sütun $\left(\underline{x}_{i j}, x_{i j}, \bar{x}_{i j}\right)$ değerlerine, 4 . sütun $\mu_{\tilde{x}_{i j}}$ ve 5 . sütun ise $\vartheta_{\tilde{x}_{i j}}$ değerleridir.

\section{Adım 6: Sezgisel Bulanık VIKOR ile Hastane Yeri Seçilmesi}

Bütünleșik değerlendirme puanları ve kriterlerin nesnel ağırlıkları elde bulunmakta olup artık sezgisel bulanık VIKOR yönteminin uygulanmasına geçilebilir. Tüm kriterler karar vericiler tarafından 
öznel olarak Tablo 2'deki dilsel ifadeler ile puanlanmıștır. Bu dilsel ifadeler Çok Kötü (ÇK) ile Çok İyi (ÇI) arasında değişmekte olup dilsel ifadelerin üçgen bulanık sayı karşılıkları da sırasıyla $(0,0,1)$ ile $(9,10,10)$ arasındadır. $\mathrm{Bu}$ da dilsel ifadelerin artan sırada dizildiğini ve eniyi değerlendirme puanının ÇI (Çok İyi) dilsel terimi ile ifade edildiğini göstermektedir. Buradan hareketle tüm kriterlerin fayda tipi olarak alınması gerektiği anlaşılmaktadır.

Tablo 6. Bütünleşik Değerlendirme Puanlarını İçeren Karar Matrisi

\begin{tabular}{|c|c|c|c|c|c|c|}
\hline \multirow{3}{*}{ Nüfus } & $\mathrm{K}$ & 4,40 & 6,40 & 8,11 & 0,8 & 0,1 \\
\hline & $\mathrm{F}$ & 5,92 & 7,92 & \begin{tabular}{|c|}
9,46 \\
\end{tabular} & 0,8 & 0,1 \\
\hline & $\mathrm{M}$ & 7,24 & 8,95 & \begin{tabular}{|l|}
9,83 \\
\end{tabular} & 0,7 & 0,2 \\
\hline \multirow{3}{*}{$\begin{array}{c}\text { Yaş } \\
\text { Dağılımı }\end{array}$} & $\mathrm{K}$ & 5,82 & 7,53 & 8,95 & 0,7 & 0,2 \\
\hline & $\mathrm{F}$ & 6,08 & 8,08 & 9,54 & 0,8 & 0,1 \\
\hline & $\mathrm{M}$ & 2,13 & 3,84 & 5,84 & 0,8 & 0,1 \\
\hline \multirow{3}{*}{$\begin{array}{c}\text { Gelir } \\
\text { Seviyesi }\end{array}$} & $\mathrm{K}$ & 7,58 & 9,29 & 10,00 & 0,7 & 0,2 \\
\hline & $\mathrm{F}$ & 4,73 & 6,73 & 8,44 & 0,8 & 0,1 \\
\hline & $\mathrm{M}$ & 5,34 & 7,34 & 9 & 0,8 & 0,1 \\
\hline \multirow{3}{*}{$\begin{array}{c}\text { Arazi } \\
\text { Maliyeti }\end{array}$} & $\mathrm{K}$ & 3,07 & 4,90 & 6,90 & 0,8 & 0,1 \\
\hline & $\mathrm{F}$ & 6,59 & 8,34 & 9,54 & 0,7 & 0,2 \\
\hline & $\mathrm{M}$ & 0,29 & 0,87 & 2,16 & 0,7 & 0,2 \\
\hline \multirow{3}{*}{$\begin{array}{c}\text { İnşaat } \\
\text { Maliyeti }\end{array}$} & $\mathrm{K}$ & 6,40 & 8,11 & 9,24 & 0,7 & 0,2 \\
\hline & $\mathrm{F}$ & 6,32 & 8,32 & 9,49 & 0,8 & 0,1 \\
\hline & $\mathrm{M}$ & 2,93 & 4,93 & 6,93 & 0,9 & 0 \\
\hline \multirow{3}{*}{$\begin{array}{c}\text { Peyzaj } \\
\text { Maliyeti }\end{array}$} & $\mathrm{K}$ & 3,82 & 5,82 & 7,82 & 0,9 & 0 \\
\hline & $\mathrm{F}$ & 5,58 & 7,58 & 9,29 & 0,8 & 0,1 \\
\hline & $\mathrm{M}$ & 5,00 & 7,00 & 8,71 & 0,8 & 0,1 \\
\hline \multirow{3}{*}{$\begin{array}{c}\text { Toplu } \\
\text { Ulaşım } \\
\text { İmkanı } \\
\end{array}$} & $\mathrm{K}$ & 0,29 & 1,41 & 3,24 & 0,7 & 0,2 \\
\hline & $\mathrm{F}$ & 5,60 & 7,44 & 8,84 & 0,7 & 0,2 \\
\hline & $\mathrm{M}$ & 7,82 & 9,24 & 9,83 & 0,7 & 0,2 \\
\hline \multirow{3}{*}{ Merkezilik } & $\mathrm{K}$ & 1,63 & 3,17 & 5,17 & 0,8 & 0,1 \\
\hline & $\mathrm{F}$ & 6,93 & 8,68 & 9,71 & 0,7 & 0,2 \\
\hline & $\mathrm{M}$ & 5,89 & 7,60 & 8,73 & 0,7 & 0,2 \\
\hline \multirow{3}{*}{$\begin{array}{c}\text { Yerleşim } \\
\text { Alanlarına } \\
\text { Yakınlik }\end{array}$} & $\mathrm{K}$ & 2,49 & 4,49 & 6,49 & 0,9 & 0 \\
\hline & $\mathrm{F}$ & 7,84 & 9,42 & 10,00 & 0,7 & 0,2 \\
\hline & $\mathrm{M}$ & 7,07 & 8,78 & 9,75 & 0,7 & 0,2 \\
\hline \multirow{3}{*}{$\begin{array}{c}\text { Eczanelere } \\
\text { Yakmlkk }\end{array}$} & $\mathrm{K}$ & 3,00 & 5,00 & 7,00 & 0,9 & 0 \\
\hline & $\mathrm{F}$ & 7,58 & 9,29 & 10,00 & 0,7 & 0,2 \\
\hline & $\mathrm{M}$ & 8,42 & 9,71 & 10,00 & 0,7 & 0,2 \\
\hline \multirow{3}{*}{$\begin{array}{l}\text { Yolculuk } \\
\text { Süresi }\end{array}$} & $\mathrm{K}$ & 0,29 & 1,12 & 2,66 & 0,7 & 0,2 \\
\hline & $\mathrm{F}$ & 7,51 & 9,25 & 10,00 & 0,7 & 0,2 \\
\hline & $M$ & 7,24 & 8,95 & \begin{tabular}{|l|}
9,83 \\
\end{tabular} & 0,7 & 0,2 \\
\hline
\end{tabular}

\begin{tabular}{|c|c|c|c|c|c|c|}
\hline \multirow{3}{*}{ Kirlilik } & $\mathrm{K}$ & 7,48 & 8,90 & 9,49 & 0,7 & 0,2 \\
\hline & $\mathrm{F}$ & 6,01 & 7,76 & 8,96 & 0,7 & 0,2 \\
\hline & $\mathrm{M}$ & 4,93 & 6,93 & 8,68 & 0,8 & 0,1 \\
\hline \multirow{3}{*}{$\begin{array}{l}\text { Hava } \\
\text { Kalitesi }\end{array}$} & $\mathrm{K}$ & 9,00 & 10,00 & 10,00 & 0,7 & 0,2 \\
\hline & $\mathrm{F}$ & 7,24 & 8,95 & 9,83 & 0,7 & 0,2 \\
\hline & $\mathrm{M}$ & 6,16 & 8,16 & 9,58 & 0,8 & 0,1 \\
\hline \multirow{3}{*}{$\begin{array}{c}\text { Şehir } \\
\text { Planına } \\
\text { Uygunluk }\end{array}$} & $\mathrm{K}$ & 8,49 & 9,75 & 10,00 & 0,7 & 0,2 \\
\hline & $\mathrm{F}$ & 7,07 & 8,78 & 9,75 & 0,7 & 0,2 \\
\hline & $\mathrm{M}$ & 5,58 & 7,58 & 9,29 & 0,8 & 0,1 \\
\hline \multirow{3}{*}{$\begin{array}{c}\text { Gürültü } \\
\text { Kaynakları }\end{array}$} & $\mathrm{K}$ & 7,41 & 8,95 & 9,75 & 0,7 & 0,2 \\
\hline & $\mathrm{F}$ & 3,68 & 5,68 & 7,42 & 0,8 & 0,1 \\
\hline & $\mathrm{M}$ & 0,46 & 1,63 & 3,34 & 0,7 & 0,2 \\
\hline \multirow{3}{*}{$\begin{array}{l}\text { Mimari } \\
\text { Tasarmm }\end{array}$} & $\mathrm{K}$ & 4,08 & 6,08 & 8,08 & 0,9 & 0 \\
\hline & $\mathrm{F}$ & 5,17 & 7,17 & 8,63 & 0,8 & 0,1 \\
\hline & $\mathrm{M}$ & 5,89 & 7,60 & 8,73 & 0,7 & 0,2 \\
\hline \multirow{3}{*}{$\begin{array}{c}\text { Park } \\
\text { Alanları }\end{array}$} & $\mathrm{K}$ & 9,00 & 10,00 & 10,00 & 0,7 & 0,2 \\
\hline & $\mathrm{F}$ & 4,40 & 6,40 & 8,11 & 0,8 & 0,1 \\
\hline & $\mathrm{M}$ & 0,25 & 1,05 & 2,59 & 0,7 & 0,2 \\
\hline \multirow{3}{*}{$\begin{array}{l}\text { Enerji } \\
\text { Temini }\end{array}$} & $\mathrm{K}$ & 3,68 & 5,68 & 7,51 & 0,8 & 0,1 \\
\hline & $\mathrm{F}$ & 7,34 & 9,17 & 10,00 & 0,7 & 0,2 \\
\hline & $\mathrm{M}$ & 7,92 & 9,46 & 10,00 & 0,7 & 0,2 \\
\hline \multirow{3}{*}{$\begin{array}{c}\text { Alan } \\
\text { Yeterliliği }\end{array}$} & $\mathrm{K}$ & 9,00 & 10,00 & 10,00 & 0,7 & 0,2 \\
\hline & $\mathrm{F}$ & 2,48 & 4,23 & 6,23 & 0,8 & 0,1 \\
\hline & $M$ & 0,76 & 1,56 & 3,10 & 0,7 & 0,2 \\
\hline \multirow{3}{*}{$\begin{array}{c}\text { Altyapı } \\
\text { Yeterliliği }\end{array}$} & $\mathrm{K}$ & 4,49 & 6,49 & 8,20 & 0,8 & 0,1 \\
\hline & $\mathrm{F}$ & 7,58 & 9,29 & 10,00 & 0,7 & 0,2 \\
\hline & $\mathrm{M}$ & 7,07 & 8,78 & 9,75 & 0,7 & 0,2 \\
\hline \multirow{3}{*}{ Rekabet } & $\mathrm{K}$ & 9,00 & 10,00 & 10,00 & 0,7 & 0,2 \\
\hline & $\mathrm{F}$ & 1,56 & 3,27 & 5,27 & 0,8 & 0,1 \\
\hline & M & 5,51 & 7,51 & 8,96 & 0,8 & 0,1 \\
\hline
\end{tabular}


Adım 6.1'de normalize karar matrisi oluşturulur. Denklem (16) kullanılarak belirlenen normalize değerler Tablo 7'de özetlenmektedir. $\mu_{\tilde{x}_{i j}}$ ve $\vartheta_{\tilde{x}_{i j}}$ derecelerinin aynen korunduğu bu tabloda $\mathrm{K}$ alternatifinin normalize değerlerinin nasıl

$$
\left(\underline{r}_{11}, r_{11}, \bar{r}_{11}\right)=\left(\frac{\underline{x}_{11}}{\bar{x}_{\max 1}}, \frac{x_{11}}{\bar{x}_{\max 1}}, \frac{\bar{x}_{11}}{\bar{x}_{\max 1}}\right)=\left(\frac{4,40}{9,83}, \frac{6,40}{9,83}, \frac{8,11}{9,83}\right)=(0,45 ; 0,65 ; 0,82)
$$

Adım 6.2'de Denklem (17) ve (18) kullanılarak sırasıyla pozitif ve negatif ideal seçenekler oluşturulmaktadır. Tablo 8'de bu ideal seçenekler oluşturulduğunu inceleyelim. $\quad \bar{x}_{\max 1}=$ $\max \{8,11 ; 9,46 ; 9,83\}=9,83$ olmak üzere ilgili normalize değer Denklem (16)'ya göre aşağıdaki gibi hesaplanır. her kriter için verilmektedir. Nüfus kriteri için ideal seçeneklerin nasıl oluşturulduğunu görelim.

Tablo 7. Normalize Karar Matrisi

\begin{tabular}{|c|c|c|c|c|c|c|}
\hline \multirow{3}{*}{ Nüfus } & $\mathrm{K}$ & 0,45 & 0,65 & 0,82 & 0,8 & 0,1 \\
\hline & $\mathrm{F}$ & 0,60 & 0,81 & 0,96 & 0,8 & 0,1 \\
\hline & $M$ & 0,74 & 0,91 & 1,00 & 0,7 & 0,2 \\
\hline \multirow{3}{*}{$\begin{array}{c}\text { Yaş } \\
\text { Dağılımı }\end{array}$} & $\mathrm{K}$ & 0,61 & 0,79 & 0,94 & 0,7 & 0,2 \\
\hline & $\mathrm{F}$ & 0,64 & 0,85 & 1,00 & 0,8 & 0,1 \\
\hline & $\mathrm{M}$ & 0,22 & 0,40 & 0,61 & 0,8 & 0,1 \\
\hline \multirow{3}{*}{$\begin{array}{c}\text { Gelir } \\
\text { Seviyesi }\end{array}$} & $\mathrm{K}$ & 0,76 & 0,93 & 1,00 & 0,7 & 0,2 \\
\hline & $\mathrm{F}$ & 0,47 & 0,67 & 0,84 & 0,8 & 0,1 \\
\hline & $\mathrm{M}$ & 0,53 & 0,73 & 0,92 & 0,8 & 0,1 \\
\hline \multirow{3}{*}{$\begin{array}{c}\text { Arazi } \\
\text { Maliyeti }\end{array}$} & $\mathrm{K}$ & 0,32 & 0,51 & 0,72 & 0,8 & 0,1 \\
\hline & $\mathrm{F}$ & 0,69 & 0,87 & 1,00 & 0,7 & 0,2 \\
\hline & $\mathrm{M}$ & 0,03 & 0,09 & 0,23 & 0,7 & 0,2 \\
\hline \multirow{3}{*}{$\begin{array}{c}\text { İnşaat } \\
\text { Maliyeti }\end{array}$} & $\mathrm{K}$ & 0,67 & 0,85 & 0,97 & 0,7 & 0,2 \\
\hline & $\mathrm{F}$ & 0,67 & 0,88 & 1,00 & 0,8 & 0,1 \\
\hline & $M$ & 0,31 & 0,52 & 0,73 & 0,9 & 0 \\
\hline \multirow{3}{*}{$\begin{array}{l}\text { Peyzaj } \\
\text { Maliyeti }\end{array}$} & $\mathrm{K}$ & 0,41 & 0,63 & 0,84 & 0,9 & 0 \\
\hline & $\mathrm{F}$ & 0,60 & 0,82 & 1,00 & 0,8 & 0,1 \\
\hline & $\mathrm{M}$ & 0,54 & 0,75 & 0,94 & 0,8 & 0,1 \\
\hline \multirow{3}{*}{$\begin{array}{c}\text { Toplu } \\
\text { Ulaşım } \\
\text { İmkanı }\end{array}$} & $\mathrm{K}$ & 0,03 & 0,14 & 0,33 & 0,7 & 0,2 \\
\hline & $\mathrm{F}$ & 0,57 & 0,76 & 0,90 & 0,7 & 0,2 \\
\hline & $\mathrm{M}$ & 0,80 & 0,94 & 1,00 & 0,7 & 0,2 \\
\hline \multirow{3}{*}{ Merkezilik } & $\mathrm{K}$ & 0,17 & 0,33 & 0,53 & 0,8 & 0,1 \\
\hline & $\mathrm{F}$ & 0,71 & 0,89 & 1,00 & 0,7 & 0,2 \\
\hline & $\mathrm{M}$ & 0,61 & 0,78 & 0,90 & 0,7 & 0,2 \\
\hline \multirow{3}{*}{$\begin{array}{c}\text { Yerleşim } \\
\text { Alanlarina } \\
\text { Yakınlk }\end{array}$} & $\mathrm{K}$ & 0,25 & 0,45 & 0,65 & 0,9 & 0 \\
\hline & $\mathrm{F}$ & 0,78 & 0,94 & 1,00 & 0,7 & 0,2 \\
\hline & $\mathrm{M}$ & 0,71 & 0,88 & 0,97 & 0,7 & 0,2 \\
\hline \multirow{3}{*}{$\begin{array}{c}\text { Eczanelere } \\
\text { Yakınlik }\end{array}$} & $\mathrm{K}$ & 0,30 & 0,50 & 0,70 & 0,9 & 0 \\
\hline & $\mathrm{F}$ & 0,76 & 0,93 & 1,00 & 0,7 & 0,2 \\
\hline & $\mathrm{M}$ & 0,84 & 0,97 & 1,00 & 0,7 & 0,2 \\
\hline \multirow{3}{*}{$\begin{array}{c}\text { Yolculuk } \\
\text { Süresi }\end{array}$} & $\mathrm{K}$ & 0,03 & 0,11 & 0,27 & 0,7 & 0,2 \\
\hline & $\mathrm{F}$ & 0,75 & 0,93 & 1,00 & 0,7 & 0,2 \\
\hline & $\mathrm{M}$ & 0,72 & 0,90 & 0,98 & 0,7 & 0,2 \\
\hline
\end{tabular}

\begin{tabular}{|c|c|c|c|c|c|c|}
\hline \multirow{3}{*}{ Kirlilik } & $\mathrm{K}$ & 0,79 & 0,94 & 1,00 & 0,7 & 0,2 \\
\hline & $\mathrm{F}$ & 0,63 & 0,82 & 0,94 & 0,7 & 0,2 \\
\hline & $\mathrm{M}$ & 0,52 & 0,73 & 0,91 & 0,8 & 0,1 \\
\hline \multirow{3}{*}{$\begin{array}{c}\text { Hava } \\
\text { Kalitesi }\end{array}$} & $\mathrm{K}$ & 0,90 & 1,00 & 1,00 & 0,7 & 0,2 \\
\hline & $\mathrm{F}$ & 0,72 & 0,90 & 0,98 & 0,7 & 0,2 \\
\hline & $\mathrm{M}$ & 0,62 & 0,82 & 0,96 & 0,8 & 0,1 \\
\hline \multirow{3}{*}{$\begin{array}{c}\text { Şehir } \\
\text { Planına } \\
\text { Uygunluk }\end{array}$} & $\mathrm{K}$ & 0,85 & 0,97 & 1,00 & 0,7 & 0,2 \\
\hline & $\mathrm{F}$ & 0,71 & 0,88 & 0,97 & 0,7 & 0,2 \\
\hline & $M$ & 0,56 & 0,76 & 0,93 & 0,8 & 0,1 \\
\hline \multirow{3}{*}{$\begin{array}{c}\text { Gürültü } \\
\text { Kaynakları }\end{array}$} & $\mathrm{K}$ & 0,76 & 0,92 & 1,00 & 0,7 & 0,2 \\
\hline & $\mathrm{F}$ & 0,38 & 0,58 & 0,76 & 0,8 & 0,1 \\
\hline & $\mathrm{M}$ & 0,05 & 0,17 & 0,34 & 0,7 & 0,2 \\
\hline \multirow{3}{*}{$\begin{array}{l}\text { Mimari } \\
\text { Tasarmm }\end{array}$} & $\mathrm{K}$ & 0,47 & 0,70 & 0,93 & 0,9 & 0 \\
\hline & $\mathrm{F}$ & 0,59 & 0,82 & 0,99 & 0,8 & 0,1 \\
\hline & $\mathrm{M}$ & 0,67 & 0,87 & 1,00 & 0,7 & 0,2 \\
\hline \multirow{3}{*}{$\begin{array}{c}\text { Park } \\
\text { Alanlar1 }\end{array}$} & $\mathrm{K}$ & 0,90 & 1,00 & 1,00 & 0,7 & 0,2 \\
\hline & $\mathrm{F}$ & 0,44 & 0,64 & 0,81 & 0,8 & 0,1 \\
\hline & $\mathrm{M}$ & 0,03 & 0,10 & 0,26 & 0,7 & 0,2 \\
\hline \multirow{3}{*}{$\begin{array}{l}\text { Enerji } \\
\text { Temini }\end{array}$} & $\mathrm{K}$ & 0,37 & 0,57 & 0,75 & 0,8 & 0,1 \\
\hline & $\mathrm{F}$ & 0,73 & 0,92 & 1,00 & 0,7 & 0,2 \\
\hline & $\mathrm{M}$ & 0,79 & 0,95 & 1,00 & 0,7 & 0,2 \\
\hline \multirow{3}{*}{$\begin{array}{c}\text { Alan } \\
\text { Yeterliliği }\end{array}$} & $\mathrm{K}$ & 0,90 & 1,00 & 1,00 & 0,7 & 0,2 \\
\hline & $\mathrm{F}$ & 0,25 & 0,42 & 0,62 & 0,8 & 0,1 \\
\hline & $\mathrm{M}$ & 0,08 & 0,16 & 0,31 & 0,7 & 0,2 \\
\hline \multirow{3}{*}{$\begin{array}{c}\text { Altyapı } \\
\text { Yeterliliği }\end{array}$} & $\mathrm{K}$ & 0,45 & 0,65 & 0,82 & 0,8 & 0,1 \\
\hline & $\mathrm{F}$ & 0,76 & 0,93 & 1,00 & 0,7 & 0,2 \\
\hline & $\mathrm{M}$ & 0,71 & 0,88 & 0,97 & 0,7 & 0,2 \\
\hline \multirow{3}{*}{ Rekabet } & $\mathrm{K}$ & 0,90 & 1,00 & 1,00 & 0,7 & 0,2 \\
\hline & $\mathrm{F}$ & 0,16 & 0,33 & 0,53 & 0,8 & 0,1 \\
\hline & $\mathrm{M}$ & 0,55 & 0,75 & 0,90 & 0,8 & 0,1 \\
\hline
\end{tabular}




$$
\begin{gathered}
\tilde{f}_{1}^{*}=\max _{1} \tilde{r}_{1 j}=\left(\left(\max _{1} \underline{r}_{1 j}, \max _{1} r_{1 j}, \max _{1} \bar{r}_{1 j}\right) ; 1,0\right)=\left(\max _{1}\left\{\begin{array}{l}
0,45 \\
0,60 \\
0,74
\end{array}\right\}, \max _{1}\left\{\begin{array}{l}
0,65 \\
0,81 \\
0,91
\end{array}\right\}, \max _{1}\left\{\begin{array}{l}
0,82 \\
0,96 \\
1,00
\end{array}\right\} ; 1,0\right) \\
\tilde{f}_{1}^{-}=\min _{1} \tilde{r}_{1 j}=\left(\left(\min _{1} \underline{r}_{1 j}, \min _{1} r_{1 j}, \min _{1} \bar{r}_{1 j}\right) ; 0,1\right)=\left(\min _{1}\left\{\begin{array}{l}
0,45 \\
0,60 \\
0,74
\end{array}\right\}, \min _{1}\left\{\begin{array}{l}
0,65 \\
0,81 \\
0,91
\end{array}\right\}, \min _{1}\left\{\begin{array}{l}
0,82 \\
0,96 \\
1,00
\end{array}\right\} ; 1,0\right)
\end{gathered}
$$

Adım 6.3'de Denklem (19) kullanılarak Hamming mesafelerine dayalı pozitif ve negatif ideal seçeneklerden göreli uzaklıklar hesaplanır. Bu adım dâhil olmak üzere buraya kadarki ișlemlerin tümü her üç veyalık derecesi için de aynı olup Adım 6.4'te ağırlık kullanılmaya başlandığı için sonuçlar farklılaşmaktadır. Tablo 9'da tüm alternatifler için belirlenen mesafeler " $d$ " sütun bloğu altında gösterilmektedir. Nüfus kriteri için yapılan ölçümü örnek olarak açlklayalım. Buradaki mesafe ölçümleri Denklem (10) ile yapılmaktadır.

Tablo 8

Pozitif ve Negatif İdeal Seçenekler

\begin{tabular}{lcccccc}
\hline & \multicolumn{5}{c}{$\mathrm{f}^{*}$} \\
\hline Nüfus & 0,74 & 0,91 & 1,00 & 0,45 & 0,65 & 0,82 \\
Yaş Dağılımı & 0,64 & 0,85 & 1,00 & 0,22 & 0,40 & 0,61 \\
Gelir Seviyesi & 0,76 & 0,93 & 1,00 & 0,47 & 0,67 & 0,84 \\
Arazi Maliyeti & 0,69 & 0,87 & 1,00 & 0,03 & 0,09 & 0,23 \\
İnşaat Maliyeti & 0,67 & 0,88 & 1,00 & 0,31 & 0,52 & 0,73 \\
Peyzaj Maliyeti & 0,60 & 0,82 & 1,00 & 0,41 & 0,63 & 0,84 \\
Toplu Ulaşım İmkânı & 0,80 & 0,94 & 1,00 & 0,03 & 0,14 & 0,33 \\
Merkezilik & 0,71 & 0,89 & 1,00 & 0,17 & 0,33 & 0,53 \\
Yerleşim Alanlarına Yakınlık & 0,78 & 0,94 & 1,00 & 0,25 & 0,45 & 0,65 \\
Eczanelere Yakınlık & 0,84 & 0,97 & 1,00 & 0,30 & 0,50 & 0,70 \\
Yolculuk Süresi & 0,75 & 0,93 & 1,00 & 0,03 & 0,11 & 0,27 \\
Kirlilik & 0,79 & 0,94 & 1,00 & 0,52 & 0,73 & 0,91 \\
Hava Kalitesi & 0,90 & 1,00 & 1,00 & 0,62 & 0,82 & 0,96 \\
Şehir Planına Uygunluk & 0,85 & 0,97 & 1,00 & 0,56 & 0,76 & 0,93 \\
Gürültü Kaynakları & 0,76 & 0,92 & 1,00 & 0,05 & 0,17 & 0,34 \\
Mimari Tasarım & 0,67 & 0,87 & 1,00 & 0,47 & 0,70 & 0,93 \\
Park Alanları & 0,90 & 1,00 & 1,00 & 0,03 & 0,10 & 0,26 \\
Enerji Temini & 0,79 & 0,95 & 1,00 & 0,37 & 0,57 & 0,75 \\
Alan Yeterliliği & 0,90 & 1,00 & 1,00 & 0,08 & 0,16 & 0,31 \\
Altyapı Yeterliliği & 0,76 & 0,93 & 1,00 & 0,45 & 0,65 & 0,82 \\
Rekabet & 0,90 & 1,00 & 1,00 & 0,16 & 0,33 & 0,53 \\
\hline
\end{tabular}

$$
d_{11}=\frac{d\left(\tilde{f}_{j}^{*}, \tilde{r}_{i j}\right)}{d\left(\tilde{f}_{j}^{*}, \tilde{f}_{j}^{-}\right)}=\frac{\frac{1}{3}[|0,74-0,45|+|0,91-0,65|+|1-0,82|]+\max (|1-0,8|,|0-0,1|)}{\frac{1}{3}[|0,74-0,45|+|0,91-0,65|+|1-0,82|]+\max (|1-0|,|0-1|)}=\frac{0,44}{1,24}=0,3556
$$


Adım 6.4'de $S_{i}$ grup faydası ve $R_{i}$ bireysel pişmanlık değerleri sirasiyla Denklem (20) ve (21) kullanılarak hesaplanır. Tablo 9'un $d^{\text {OWA }}$ sütun bloğu altında her bir alternatif için belirlenen mesafeler azalan sirada listelenmektedirler. Tablo 10 'da her alternatif için $w_{j} d_{i j}^{O W A}$ çarpımları verilmekteolup Tablo 11'de duyarlılık analizine yönelik olarak üç farklı veyalık derecesi için belirlenen ağırlıklarla hesaplanan $\mathrm{S}, \mathrm{R}$ ve $\mathrm{Q}$ değerleri gösterilmektedir. Tablo 11, üç alt bölümden oluşmakta olup (a), (b) ve (c), sirasiyla 0,$25 ; 0,50$ ve 0,75 veyalı dereceleriyle belirlenen ağırlıklar kullanıldığında hangi $S$, $R$ ve $Q$ değerlerinin bulunduğunu göstermektedir.

Adım 6.5'te bir önceki adımda bulunan $\mathrm{S}$ ve $\mathrm{R}$ değerleri kullanılarak Q indeksi hesaplanmaktadır. Denklem (22)'nin kullanıldığı bu adımda $v$ strateji katsayısı 0,5 olarak alınmıştır. Bu seçimin anlamı bireysel pişmanlık (R) ve grup uzlaşısına (S) eșit önemi vermektir. Tablo 11'de özetlenen duyarlılık analizinin her alt bölümünde $\mathrm{Q}$ değerleri görülmektedir.

Tablo 9

Alternatifler için Uzaklık Ölçümleri

\begin{tabular}{|c|c|c|c|c|c|c|}
\hline & \multicolumn{3}{|c|}{$d$} & \multicolumn{3}{|c|}{ dOWA } \\
\hline & $K$ & $F$ & $M$ & $K$ & $F$ & $M$ \\
\hline Nüfus & 0,3556 & 0,2357 & 0,2417 & 0,6014 & 0,5093 & 0,6189 \\
\hline Yaş Dağılımı & 0,2469 & 0,1413 & 0,4347 & 0,5987 & 0,4118 & 0,6081 \\
\hline Gelir Seviyesi & 0,2435 & 0,3506 & 0,2982 & 0,4761 & 0,3506 & 0,5975 \\
\hline Arazi Maliyeti & 0,3077 & 0,1725 & 0,5975 & 0,4076 & 0,3454 & 0,5900 \\
\hline İnşaat Maliyeti & 0,2378 & 0,1521 & 0,3238 & 0,3834 & 0,3411 & 0,4347 \\
\hline Peyzaj Maliyeti & 0,2367 & 0,1696 & 0,2224 & 0,3740 & 0,3252 & 0,3295 \\
\hline Toplu Ulaşım İmkânı & 0,5987 & 0,2692 & 0,1720 & 0,3630 & 0,3041 & 0,3263 \\
\hline Merkezilik & 0,4761 & 0,1965 & 0,2660 & 0,3556 & 0,2922 & 0,3238 \\
\hline Yerleşim Alanlarına & 0,3834 & 0,2055 & & & & \\
\hline Yakınlık & & & 0,2436 & 0,3077 & 0,2692 & 0,3165 \\
\hline Eczanelere Yakınlık & 0,3740 & 0,2380 & 0,2087 & 0,2563 & 0,2435 & 0,2982 \\
\hline Yolculuk Süresi & 0,6014 & 0,1708 & 0,1848 & 0,2526 & 0,2389 & 0,2725 \\
\hline Kirlilik & 0,2526 & 0,3454 & 0,3263 & 0,2514 & 0,2380 & 0,2662 \\
\hline Hava Kalitesi & 0,2563 & 0,3411 & 0,3165 & 0,2469 & 0,2341 & 0,2660 \\
\hline Şehir Planına Uygunluk & 0,2514 & 0,3252 & 0,3295 & 0,2435 & 0,2154 & 0,2605 \\
\hline Gürültü Kaynakları & 0,1757 & 0,3041 & 0,5900 & 0,2378 & 0,2055 & 0,2436 \\
\hline Mimari Tasarım & 0,2184 & 0,2154 & 0,2605 & 0,2367 & 0,1965 & 0,2400 \\
\hline Park Alanları & 0,1633 & 0,2922 & 0,6189 & 0,2184 & 0,1725 & 0,2224 \\
\hline Enerji Temini & 0,4076 & 0,2435 & 0,2221 & 0,1840 & 0,1708 & 0,2221 \\
\hline Alan Yeterliliği & 0,1680 & 0,4118 & 0,6081 & 0,1757 & 0,1696 & 0,2087 \\
\hline Altyapı Yeterliliği & 0,3630 & 0,2389 & 0,2725 & 0,1680 & 0,1521 & 0,1848 \\
\hline Rekabet & 0,1840 & 0,5093 & 0,2662 & 0,1633 & 0,1413 & 0,1720 \\
\hline
\end{tabular}

Adım 6.6'da alternatifler $S$, $R$ ve $Q$ değerlerine göre sıralanmakta ve Adım 6.7'de verilen koșulların denetlenmesi ile uzlaşık çözüme ulașılmaktadır. Tablo 11'in her alt bölümünün son iki satırında bu koşullara ilişkin denetim sonuçları verilmektedir.
Buna göre, her üç veyalık derecesi için de sıralamalar değişmemiş ve F, İstanbul'un bu ilçesi için eniyi hastane yeri olarak seçilmiş olmaktadır. 
Tablo 10

Ağırlıklandırılmış Uzaklıklar

\begin{tabular}{cccccccc}
\hline \multicolumn{7}{c}{$w d^{\text {OWA }}$} \\
& $K$ & $F$ & $M$ & & $K$ & $F$ & $M$ \\
\hline 1 & 0,0037 & 0,0032 & 0,0038 & 13 & 0,0105 & 0,0100 & 0,0113 \\
2 & 0,0044 & 0,0030 & 0,0044 & 14 & 0,0122 & 0,0108 & 0,0130 \\
3 & 0,0041 & 0,0030 & 0,0051 & 15 & 0,0139 & 0,0121 & 0,0143 \\
4 & 0,0041 & 0,0035 & 0,0059 & 16 & 0,0163 & 0,0135 & 0,0165 \\
5 & 0,0045 & 0,0040 & 0,0051 & 17 & 0,0176 & 0,0139 & 0,0180 \\
6 & 0,0052 & 0,0045 & 0,0046 & 18 & 0,0175 & 0,0162 & 0,0211 \\
7 & 0,0059 & 0,0049 & 0,0053 & 19 & 0,0196 & 0,0189 & 0,0232 \\
8 & 0,0068 & 0,0056 & 0,0062 & 20 & 0,0220 & 0,0199 & 0,0242 \\
9 & 0,0069 & 0,0060 & 0,0071 & 21 & 0,0251 & 0,0217 & 0,0264 \\
10 & 0,0067 & 0,0064 & 0,0078 & $\mathrm{~S}$ & 0,2239 & 0,1970 & 0,2414 \\
11 & 0,0078 & 0,0074 & 0,0084 & $\mathrm{R}$ & 0,0251 & 0,0217 & 0,0264 \\
12 & 0,0091 & 0,0086 & 0,0096 & $\mathrm{Q}$ & 0,6610 & 0,0000 & 1,0000 \\
\hline
\end{tabular}

Tablo 11

S-R-Q Değerleri ve Uzlaşık Çözüm

\begin{tabular}{ccccccc}
\hline & \multicolumn{5}{c}{ veyalik(w)=0,25 } \\
& $\mathrm{S}$ & $\mathrm{R}$ & $\mathrm{Q}$ \\
\hline $\mathrm{K}$ & 0,2238 & 2 & 0,0251 & 2 & 0,6610 & 2 \\
$\mathrm{~F}$ & 0,1970 & 1 & 0,0217 & 1 & 0,0000 & 1 \\
$\mathrm{M}$ & 0,2414 & 3 & 0,0264 & 3 & 1,0000 & 3 \\
& Koşul 1: & & $0,6610-0=0,6610 \geq 1 / 2=0,5$ & \\
& Koşul 2: & & S, R ve Q'deeniyi alternatif F.
\end{tabular}

(a) 0,25 veyalı $\mathrm{k}$ derecesi için

\begin{tabular}{ccccccc}
\hline & \multicolumn{5}{c}{ veyalık $(\mathrm{w})=0,5$} \\
& $\mathrm{~S}$ & & $\mathrm{R}$ & $\mathrm{Q}$ & \\
\hline $\mathrm{K}$ & 0,3098 & 2 & 0,0286 & 2 & 0,7522 & 2 \\
$\mathrm{~F}$ & 0,2632 & 1 & 0,0243 & 1 & 0,0000 & 1 \\
$\mathrm{M}$ & 0,3335 & 3 & 0,0295 & 3 & 1,0000 & 3 \\
& Koşul 1: & \multicolumn{5}{c}{$0,7522-0=0,7522 \geq 1 / 2=0,5$} \\
& Koşul 2: & \multicolumn{5}{c}{ S, R ve Q'deeniyi alternatif F. }
\end{tabular}

(b) 0,50 veyalı derecesi için

\begin{tabular}{ccccccc}
\hline & \multicolumn{5}{c}{ veyalık(w)=0,75 } \\
& $\mathrm{S}$ & & $\mathrm{R}$ & $\mathrm{Q}$ \\
\hline $\mathrm{K}$ & 0,4205 & 2 & 0,0923 & 2 & 0,7605 & 2 \\
$\mathrm{~F}$ & 0,3427 & 1 & 0,0781 & 1 & 0,0000 & 1 \\
$\mathrm{M}$ & 0,4570 & 3 & 0,0950 & 3 & 1,0000 & 3 \\
& Koşul 1: & & $0,7605-0=0,7605$ & $1 / 2=0,5$ \\
& Koşul 2: & \multicolumn{5}{c}{$\mathrm{S}, \mathrm{R}$ ve Q'deeniyi alternatif F. } \\
& \multicolumn{5}{c}{ (c) 0,75 veyalık derecesi için } \\
\hline
\end{tabular}




\section{Sonuçlar ve Tartışma}

Kentlerin kalabalıklaşması ve kültürel çeşitliliğin göç dalgaları ile birlikte artması ile kentlerdeki sağlık hizmetleri yetersizleșebilmekte, toplum ve birey sağlı̆̆ının daha etkin bir şekilde korunabilmesi için yeni hastanelerin kurulmasına gerek duyulabilmektedir. $\mathrm{Bu}$ çalışmada yeni hastanelerin kurulabileceği eniyi yerin belirlenmesine yönelik olarak bir çok kriterli karar destek modeli önerisi getirilmektedir. Modelde, öncelikle uzmanlardan oluşan bir ekip kurulmakta, bu ekip yazın taramasının sonuçlarını da dikkate alarak kriter kümesini belirlemekte ve alternatif hastane yerlerini bu kriterlere göre değerlendirmektedir. Önerilen modeli, yazındaki mevcut modellerden ayıran üç önemli özellik aşağıda özetlenmektedir.

i. Uzman görüşlerinde insan zihninin ve tercihlerinin doğası gereği bir kararsızlık ya da kararlarda ani değişiklik olması olanak dâhilindedir. Uzman görüşlerindeki bu belirsizliği sayısal olarak eniyi şekilde değerlendirme yollarından biri olan sezgisel bulanık sayılar, çalışmada tercih edilmiştir. Bu tip bulanık sayıların klasik bulanık sayılardan en önemli farkı, üye olma derecelerinin yanı sıra bir de üye olmama ve kararsız kalmaya ilişkin üyelik derecelerinin hesaba katıliyor olmasıdır. Çalışmanın hastane yeri seçimi yazınına yaptığı en önemli katkı bu uygulamaya ilişkindir.

ii. Önerilen modelde bir grup karar verme yaklaşımı takip edilmekte, yapılan tartışmalar ve görüşmeler sonrasında uzmanların yapacakları bireysel değerlendirmeler bütünleşik olarak tek bir modelde birleştirilerek çözümlenmektedir. Yazında yer seçimi konusunda grup kararı verilmesine yönelik çalıșmalar bulunmakta, ancak hastane yeri seçimi konusunda grup kararı verilmesi amacına vurgu yapan çalışmalar özellikle son yıllarda ortaya çımaktadır. Bu çalışmada da uzmanların görüşlerinin farklı ağırlıklarla hesaba katılması ile hastane yeri seçiminde grup yargısına ulaşılması konusundaki yazına bu yönde bir katkı sunulmaya çalışılmaktadır.

iii. Alternatiflerin değerlendirilmeleri zaten öznel uzman görüşlerine dayandığı için, mevcut öznelliğin azaltılabilmesi amacıyla nesnel, yani uzman görüşünden bağımsız bir kriter ağırlıklandırma yöntemi tercih edilmiștir. Yazındaki öznel ve nesnel ağırlıklandırma yöntemleri incelenmiș, klasik yöntemlerin zayıf yönleri göz önüne alınarak nesnel ağırlıklandırma yöntemlerinden OWA yönteminde karar kılınmıştır. Bu yolla, hastane yeri seçiminde uzman görüşlerinden kaynaklanan öznelliğin azaltılması yönünde çaba gösterilmiştir.

Çalışmanın ileriki aşamaları için bir takım geliștirme olanakları da söz konusudur. Önerilen modelde sadece uzmanların değerlendirmeleri kullanılmaktadır. Nesnelliğin ve tarafsızlığın arttırılabilmesi adına mümkün olan kriterlerde ölçümleme sonuçlarının doğrudan kullanılması seçeneği de değerlendirilebilir. Örneğin, maliyetlerle ilgili kriterlerde maliyetin kendi değeri hesaba katılabilir. Ayrıca, bu çalışmada kriterler arasındaki ilişkiler göz ardı edilmiştir. Gelecek çalıșmalarda kriterler arası olası ilișkilerin belirlenmesine yönelik olarak uygulamalar geliştirilebilir, uygun yöntemler ile bu ilişkiler belirlendikten sonra karar modeli içerisinde düzenlemeler yapılarak bu ilişkiler de karar sürecine dâhil edilebilir.Son olarak, VIKOR yöntemi içerisinde yer alan ve karar verici tarafından soruna özgü olarak belirlenen v strateji katsayısına yönelik ek bir duyarlılık analizi yapılabilir ve böylelikle bu parametredeki değişimlerin seçenek sıralamasını nasıl etkilediği gözlemlenebilir. Böylelikle de soruna ilişkin daha kapsamlı bir görüş oluşturulabilir.

\section{Çıkar Çatışması}

Yazarlar tarafından herhangi bir çıkar çatışması beyan edilmemiştir.

\section{Kaynaklar}

Adall, E.A. \& Tuş, A. (2019). Hospital site selection with distance-based multi-criteria decisionmaking methods. International Journal of Healthcare Management. Doi: https:// doi.org/10.1080/20479700.2019.1674005.

Ahmed, A.H., Mahmoud, H., \& Aly, A.M.M. (2016). Site Suitability Evaluation for Sustainable Distribution of Hospital Using Spatial Information Technologies and AHP: A Case Study of Upper Egypt, Aswan City. Journal of Geographic Information System, 8, 578-594. Doi: https://doi.org/10.4236/igis.2016.85048.

Ajaj, Q.M., Shareef, M.A., Jasim, A.T., Hasan, S.F., Noori, A.M., \& Hassan, N.D. (2019). An AHP-based 
GIS for a New Hospital Site Selection in the Kirkuk Governorate, 2nd International Conference on Electrical, Communication, Computer, Powerand Control Engineering, Mosul,Iraq, 176-181. Doi: https://doi.org/10.1109/ ICECCPCE46549.2019. 203769.

Arya, V. \& Kumar, S. (2020). A new Picture fuzzy information measure based on shannon entropy with applications in opinion polls using extended VIKOR-TODIM approach. Computational and Applied Mathematics, 39(3), 1-24. Doi: https://doi.org/10.1007/s40314-02001228-1.

Atanassov, K.T. (1986). Intuitionistic fuzzy sets. Fuzzy Sets and Systems, 20, 87-96. Doi: https://doi.org/10.1016/S0165-0114(86)80034-3.

Aydın, Ö. (2009). Bulanık AHP ile Ankara için Hastane Yeri Seçimi. Dokuz Eylül Üniversitesi Íktisadi ve Ídari Bilimler Fakültesi Dergisi, 24(2), 87-104. Erişim adresi: https://iibfdergi.deu.edu.tr/index.php/cilt1sayi1/article/view/260.

Aydın, Ö., Öznehir, S., \& Akçalı, E. (2009). Ankara için Optimal Hastane Yeri Seçiminin Analitik Hiyerarşi Süreci ile Modellenmesi. Süleyman Demirel Üniversitesi Íktisadi ve İdari Bilimler Fakültesi Dergisi, 14(2), 69-86. Erişim adresi: https://dergipark.org.tr/en/download/articlefile/194657.

Barukab, O., Abdullah, S., Ashraf, S., Arif, M., \& Khan, S.A. (2019). A New Approach to Fuzzy TOPSIS Method Based on Entropy Measure under Spherical Fuzzy Information. Entropy, 21(12), 1231. Doi: https://doi.org/10.3390/e21121231.

Chatterjee, D. \& Mukherjee, B. (2013). Potential Hospital Location Selection using AHP: A Study in Rural India. International Journal of Innovative Technology and Research, 1(4), 304-314. Doi: https://doi.org/10.5120/12447-9144.

Chiu, J.E. \& Tsai, H.H. (2013). Applying analytic hierarchy process to select optimal expansion of hospital location: The case of a regional teaching hospital in Yunlin, 10th International Conference on Service Systems and Service Management,
Hong Kong, China. Doi: https://doi.org/10.1109/ICSSSM.2013.6602588.

Çelikbilek, Y. (2018). Group Decision Making for Hospital Location Selection Using VIKOR under Fuzzy Environment. İstanbul Gelişim Üniversitesi Sağlık Bilimleri Dergisi, 5, 435-450. Doi: https://doi.org/10.38079/igusabder.425439.

Dehe, B. \& Bamford, D. (2015). Development, test and comparison of two Multiple Criteria Decision Analysis (MCDA) models: A case of healthcare infrastructure location. Expert Systems with Applications, 42, 6717-6727. Doi: https://doi.org/10.1016/j.eswa.2015.04.059.

Dell'Ovo, M., Capolongo, S., \&Oppio, A. (2018). Combining spatial analysis with MCDA for the siting of healthcare facilities. Land Use Policy, 76, 634-644. Doi: $\quad$ https://doi.org/10.1016/ j.landusepol.2018.02.044.

Fuller, R. \& Majlender, P. (2003). On obtaining minimal variability OWA operatör weights. Fuzzy Sets and Systems, 136, 203-215. Doi: https://doi.org/10.1016/S0165-0114(02) 00267-1.

Gibson, J.L., Martin, D.K., \& Singer, P.A. (2004). Setting priorities in healthcare organizations: criteria, processes, and parameters of success. BMC Health Services Research, 4(25). Doi: https://doi.org/10.1186/1472-6963-4-25.

Gupta, P., Mehlawat, M.K., \& Grover, N. (2016). Intuitionistic fuzzy multi-attribute group decision-making with an application to plant location selection based o a new extended VIKOR method. Information Sciences, 370-371, 184-203. Doi: https://doi.org//10.1016/ j.ins.2016.07.058.

Han, R.C. \& Xiao, J.X. (2009). Deciding weighing by entropy value method is an error, 2nd International Conference on Information and Computing Science, Manchester-UK, 255-257. Doi: https://doi.org/10.1109/ICIC.2009.270.

Jordan, H., Roderick, P., Martin, D., \& Barnett, S. (2004). Distance, rurality and the need for care: Access to health services in South West England. International Journal of Health Geographics, 3(21). Doi: https://doi.org/10.1186/1476-072X$\underline{3-21}$. 
Kaaffah, S., Ridwan, A.Y., \& Novitasari, N. (2020). Designing Vendor Selection System Using Intuitionistic Fuzzy TOPSIS and Entropy Weighting Method in Oil and Gas Industry, ICONETSI: Proceedings of the International Conference on Engineering and Information Technology for Sustainable Industry, September 2020, Article No: 52, Pages: 1-6. Doi: https://doi.org/10.1145/3429789.3429842.

Kaya, T. \& Kahraman, C. (2011). Fuzzy multiple criteria forestry decision making based on an integrated VIKOR and AHP approach. Expert Systems with Applications, 38, 7326-7333. Doi: https://doi.org/10.1016/j.eswa.2010.12.003.

Kim, J.I., Senaratna, D.M., Ruza, J., Kam, C., \& Ng, S. (2015). Feasibility Study on an Evidence-Based Decision-Support System for Hospital Site Selection for an Aging Population, Sustainability, 7, 2730-2744. Doi: https://doi.org/ $10.3390 /$ su7032730.

Koksalmis, S. \& Kabak, Ö. (2019). Deriving decision makers' weights in group decision making: An overview of objective methods. Information Fusion, 49, 146-160. Doi: https://doi.org/ 10.1016/i.inffus.2018.11.009.

Kuo, Y.C., Lu, S.T., Tzeng, G.H., Lin, Y.C., \& Huang, Y.S. (2013). Using Fuzzy Integral Approach to Enhance Site Selection Assessment - A Case Study of the Optoelectronics Industry. Procedia Computer Science, 17, 306-313. Doi: https://doi.org/10.1016/j.procs.2013.05.040.

Li, D.F. (2010). A ratio ranking method of triangular intuitionistic fuzzy numbers and its application to MADM problems. Computers \& Mathematics with Applications, 60(6), 1557-1570. Doi: https://doi.org/10.1016/j.camwa.2010.06.039.

Liao, H. \& Xu, Z. (2013). A VIKOR-based method for hesitant fuzzy multi-criteria decision making. Fuzzy Optimization and Decision Making, 12(4), 373-392. Doi: https://doi.org/10.1007/s10700013-9162-0.

Liu, K.M., Lin, S.H., Hsieh, J.C., \& Tzeng, G.H. (2018). Improving the food waste composting facilities site selection for sustainable development using a hybrid modified MADM model. Waste
Management, 75, 44-59. Doi: https://doi.org/10.1016/j.wasman.2018.02.017.

Liu, P. \& Liu, W. (2019). Multiple-attribute group decision-making method of linguistic q-rung orthopair fuzzy power Muirhead mean operators based on entropy weight. International Journal of Intelligent Systems, 34(8), 1755-1794. Doi: https://doi.org/ 10.1002/int.22114.

Mahmud, T., Sikder, J., \& Tripura, S. (2018). Knowledge-based Decision Support System to Select Hospital Location. IOSR Journal of Computer Engineering, 20(3), 39-47. Doi: https://doi.org/10.9790/0661-2003023947.

Moradian, M.J., Ardalan, A., Nejati, A., Boloorani, A.D., Akbarisari, A., \& Rastegarfar, B. (2017). Risk Criteria in Hospital Site Selection: A Systematic Review. PLoS Currents. Doi: https://doi.org/10.1371/currents.dis.a6f34643f 3cd22c168b8c6f2deeae86d.

Nobre, F.F., Trotta, L.T.F., \& Gomes, L.F.A.M. (1999). MULTI-CRITERIA DECISION MAKING - AN APPROACH TO SETTING PRIORITIES IN HEALTH CARE. Statistics in Medicine, 18, 33453354. Doi: https://doi.org/10.1002/(SICI)10970258(19991215)18:23<3345::AIDSIM321>3.0.CO;2-7.

O'Hagan, M. (1988). Aggregating template or rule antecedents in real-time expert systems with fuzzy set logic. Proceedings of the 22nd Annual IEEE Asilomar Conference on Signal, Systems, Computers, 681-689. Pacific Grov. Doi: https://doi.org/10.1109/ACSSC.1988.754637.

Opricovic, S. (1998). Multicriteria optimization of çivil engineering, Faculty of Civil Engineering, Belgrade. Erişim adresi : https://www.scirp.org/(S(351jmbntvnsjt1aadk poszje))/reference/ReferencesPapers.aspx?Refe renceID=1600129.

Opricovic, S. (2011). Fuzzy VIKOR with an Application to Water Resources Planning. Expert Systems with Applications, 38(10), 12983-12990. Doi: https://doi.org/10.1016/ i.eswa.2011. $\underline{04.097 .}$. 
Opricovic, S. \& Tzeng, G.H. (2004). Extended VIKOR method in comparis on with outranking methods. European Journal of Operational Research, 178(2), 514-529. Doi: https://doi.org/10.1016/j.ejor.2006.01.020.

Rikalovic, A., Cosic, I., \& Lazarevic, D. (2014). GIS Based Multi-criteria Analysis for Industrial Site Selection. Procedia Engineering, 69, 1054-1063. Doi: $\quad$ https://doi.org/10.1016/i.proeng. 2014.03.090.

Ruan, D., Kabak, Ö., \& Quinones, R. (2013). An ordered weighted averaging operator-based cumulative belief degree approach for energy policy evaluation. International Journal of Advanced Operations Management, 5(1), 58-73. Doi: https://doi.org/10.1504/IJAOM.2013.051326.

Sen, H. (2017). HOSPITAL LOCATION SELECTION WITH ARAS-G. The Eurasia Proceedings of Science, Technology, Engineering \& Mathematics, 1, 359-365. Erişim adresi : https://dergipark.org.tr/tr/download/articlefile/381446.

Senvar, O., Otay, I., \& Bolturk, E. (2016). Hospital Site Selection via Hesitant Fuzzy TOPSIS. IFACPapers On Line, 49(12), 1140-1145. Doi: https://doi.org/10.1016/i.ifacol.2016.07.656.

Soltani, A., Inaloo, R.B., Rezaei, M., Shaer, F., \& Riyabi, M.A. (2019). Spatial analysis and urban land use planning emphasising hospital site selection: a case study of Isfahan city. Bulletin of Geography. Socio-economic Series, 43, 71-89. Doi: https://doi.org/10.2478/bog-2019-0005.

Soltani, A. \& Marandi, Z. (2011). HOSPITAL SITE SELECTION USING TWO-STAGE FUZZY MULTICRITERIA DECISION MAKING PROCESS. Journal of Urban and Environmental Engineering, 5(1), 32-43. Doi: https://doi.org/10.4090/juee.2011. v5n1.032043.

Song, L., Liu, C., \& Li, B. (2015). Optimal selection of location for community hospitals a case of Huilong guan region in Beijing, IEEE International Conference on Information and Automation, Lijiang, China, 2803-2806. Doi: https://doi.org/10.1109/ICInfA.2015.7279763.
Stern, Z.S., Mehrez, A., Tal, A.G., \& Shemuel, B. (1995). THE LOCATION OF A HOSPITAL IN A RURAL REGION: THE CASE OF THE NEGEV. Location Science, 3(4), 255-266. Doi: https://doi.org/10.1016/0966-8349(96)00002-2.

Şahin, T., Ocak, S., \& Top, M. (2019). Analytic hierarchy process for hospital site selection. Health Policy and Technology, 8, 42-50. Doi: https://doi.org/10.1016/i.hlpt.2019.02.005.

Vahidnia, M.H., Alesheikh, A.A., \& Alimohammadi, A. (2009). Hospital site selection using fuzzy AHP and its derivatives. Journal of Environmental Management, 90, 3048-3056. Doi: https://doi.org/10.1016/j.buildenv.2005.12.01.

Wang, Y.M. \& Parkan, C. (2005). A minimax disparity approach for obtaining OWA operatör weights. Information Sciences, 175, 20-29. Doi: https://doi.org/10.1016/i.ins.2004.09.003.

Weber, A. (1909). Theory of the location of industries, Chicago: The University of Chicago Press.

Wissem, E., Ahmed, F., \& Mounir, B. (2011). Multicriteria method for a site selection of a new hospital in Sfax, 4th International Conference on Logistics, Hammamet, Tunusia, 32-37. Doi: https://doi.org/10.1109/LOGISTIQUA.2011.5939399.

Wu, C.R., Lin, C.T., \& Chen, H.C. (2007). Optimal selection of location for Taiwanese hospitals to ensure a competitive advantage by using the analytic hierarchy process and sensitivity analysis. Building and Environment, 42, 14311444. Doi: $\quad$ https://doi.org/10.1016/ j.jenvman.2009.04.01.

Wu, Y., Liao, M., Hu, M., Lin, J., Zhou, J., Zhang, B. \& $\mathrm{Xu}, \mathrm{C}$. (2020). A decision framework of lowspeed wind farm projects in hilly areas based on DEMATEL-entropy-TODIM method from the sustainability perspective: A case in China. Energy, 213, $119014 . \quad$ Doi: https://doi.org/10.1016/i.energy.2020.119014.

Wu, Y., Zhang, B., Xu, C., \& Li, L. (2018). Site selection decision framework using fuzzy ANP-VIKOR for large commerical rooftop PV system based on sustainability perspective. Sustainable Cities and 
Society, 40, 454-470. Doi: https://doi.org/10.1016/j.scs.2018.04.024.

Yager, R.R. (1988). On ordered weighted averaging aggregation operators in multi-criteria decision making. IEEE Transactions on Systems, Man and Cybernetics, 18(1), 183-190. Doi: https://doi.org/10.1109/21.87068.

Yu, L. \& Lai, K.K. (2011). A distance-based group decision-making methodology for multi-person multi-criteria emergency decision support. Decision Support Systems, 51, 307-315. Doi: https://doi.org/10.1016/j.dss.2010.11.024.
Zadeh, L.A. (1965). Fuzzy sets. Information and Control, 8, 338-353. Doi: https://doi.org/10.1016/S00199958(65)90241-X.

Zhang, Y., Zhang, Y., Li, Y., Liu, S., \& Yang, J. (2017). A Study of Rural Logistics Center Location Based on Intuitionistic Fuzzy TOPSIS. Mathematical Problems in Engineering. Doi: https://doi.org/10.1155/2017/2323057. 


\section{EK 1. YAZIN ÖZETINE İLIŞKİN TABLO}

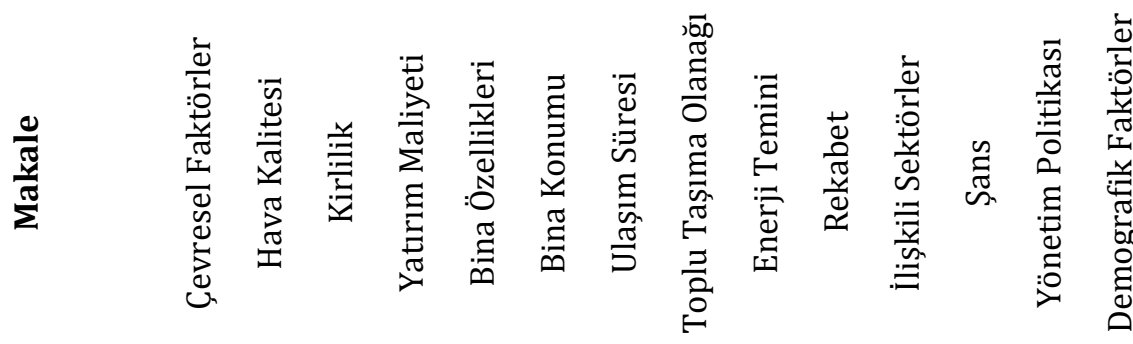

- 0-1 Tamsayılı

Stern ve diğ.

(1995)

$\mathrm{X} \quad \mathrm{X} \quad \mathrm{X}$

$\mathrm{X}$

X

Nobre, Trotta

ve Gomes

(1999)

Gibson ve diğ.

(2004)

Jordan ve diğ.

(2004)

Wu ve diğ.

(2007)

X X

X X

X X

x

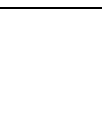




\begin{tabular}{|c|c|c|c|c|c|c|c|c|c|c|c|c|c|c|c|}
\hline $\begin{array}{l}\text { Song, Liu ve Li } \\
\text { (2015) }\end{array}$ & & & & & & $\mathrm{X}$ & & & $\mathrm{X}$ & $\mathrm{X}$ & & & $\mathrm{X}$ & Optimizasyon & Beijing, Çin \\
\hline $\begin{array}{l}\text { Ahmed ve diğ. } \\
(2016)\end{array}$ & $\mathrm{X}$ & $\mathrm{X}$ & $\mathrm{X}$ & & & $\mathrm{X}$ & $\mathrm{X}$ & $\mathrm{X}$ & & & & & & $\begin{array}{l}\text { - CBS } \\
\text { - AHS } \\
\end{array}$ & $\begin{array}{c}\text { Aswan, } \\
\text { Misır }\end{array}$ \\
\hline $\begin{array}{l}\text { Senvar ve diğ. } \\
(2016)\end{array}$ & & & & $X$ & $\mathrm{X}$ & $\mathrm{X}$ & $\mathrm{X}$ & $\mathrm{X}$ & $\mathrm{X}$ & $\mathrm{X}$ & & $\mathrm{X}$ & $\mathrm{X}$ & $\begin{array}{c}\text { Tereddütlü } \\
\text { Bulanık TOPSIS }\end{array}$ & $\begin{array}{c}\text { İstanbul, } \\
\text { Türkiye }\end{array}$ \\
\hline $\begin{array}{l}\text { Moradian, } \\
\text { Ardalan, Nejati, } \\
\text { Boloorani, } \\
\text { Akbarisari ve } \\
\text { Rastegarfar } \\
(2017) \\
\end{array}$ & $\mathrm{X}$ & $\mathrm{X}$ & $\mathrm{X}$ & $X$ & $\mathrm{X}$ & $\mathrm{X}$ & $\mathrm{X}$ & $\mathrm{X}$ & $\mathrm{X}$ & $\mathrm{X}$ & $\mathrm{X}$ & $\mathrm{X}$ & $\mathrm{X}$ & PRISMA & - \\
\hline Sen (2017) & $\mathrm{X}$ & & & $\mathrm{X}$ & $\mathrm{X}$ & $\mathrm{X}$ & $\mathrm{X}$ & $\mathrm{X}$ & & & & $\mathrm{X}$ & & ARAS-G & Türkiye \\
\hline $\begin{array}{l}\text { Çelikbilek } \\
(2018)\end{array}$ & & & & $X$ & & $\mathrm{X}$ & $\mathrm{X}$ & $\mathrm{X}$ & $\mathrm{X}$ & & & & $\mathrm{X}$ & Bulanık VIKOR & Türkiye \\
\hline $\begin{array}{l}\text { Dell'Ovo ve diğ. } \\
(2018)\end{array}$ & $\mathrm{X}$ & & & $\mathrm{X}$ & & $\mathrm{X}$ & $\mathrm{X}$ & $\mathrm{X}$ & $\mathrm{X}$ & & & & & $\begin{array}{l}- \text { CBS } \\
\text { - AHS } \\
\end{array}$ & $\begin{array}{c}\text { Milano, } \\
\text { İtalya }\end{array}$ \\
\hline $\begin{array}{l}\text { Mahmud, } \\
\text { Sikdar ve } \\
\text { Tripura (2018) }\end{array}$ & $\mathrm{X}$ & & & $\mathrm{X}$ & $\mathrm{X}$ & $\mathrm{X}$ & $\mathrm{X}$ & $\mathrm{X}$ & & & & $\mathrm{X}$ & & $\begin{array}{l}\text { Kanıt Temelli } \\
\text { Muhakeme }\end{array}$ & $\begin{array}{l}\text { Chittagong, } \\
\text { Bangladeş }\end{array}$ \\
\hline $\begin{array}{l}\text { Adalı ve Tuş } \\
\text { (2019) }\end{array}$ & $\mathrm{X}$ & $\mathrm{X}$ & $\mathrm{X}$ & $\mathrm{X}$ & & $\mathrm{X}$ & $\mathrm{X}$ & $\mathrm{X}$ & $\mathrm{X}$ & & & $\mathrm{X}$ & $\mathrm{X}$ & $\begin{array}{l}\text { - CRITIC } \\
\text { - TOPSIS } \\
\text { - EDAS } \\
\text { - CODAS }\end{array}$ & $\begin{array}{l}\text { Denizli, } \\
\text { Türkiye }\end{array}$ \\
\hline $\begin{array}{l}\text { Ajaj ve diğ. } \\
(2019)\end{array}$ & & & & & $\mathrm{X}$ & $\mathrm{X}$ & $\mathrm{X}$ & $\mathrm{X}$ & $\mathrm{X}$ & & & & & $\begin{array}{l}- \text { CBS } \\
- \text { AHS } \\
\end{array}$ & Kerkük, Irak \\
\hline $\begin{array}{l}\text { Soltani ve diğ. } \\
(2019)\end{array}$ & & & & & & $\mathrm{X}$ & $\mathrm{X}$ & & $\mathrm{X}$ & & & & $\mathrm{X}$ & $\begin{array}{l}\text { - CBS } \\
- \text { AHS } \\
\end{array}$ & İsfahan, İran \\
\hline $\begin{array}{l}\text { Şahin ve diğ. } \\
(2019)\end{array}$ & $\mathrm{X}$ & $\mathrm{X}$ & & & & $\mathrm{X}$ & $\mathrm{X}$ & & $\mathrm{X}$ & $\mathrm{X}$ & & $\mathrm{X}$ & $\mathrm{X}$ & AHS & $\begin{array}{c}\text { Muğla, } \\
\text { Türkiye }\end{array}$ \\
\hline $\begin{array}{l}\text { Queensland } \\
(2008)\end{array}$ & $\mathrm{X}$ & & & $\mathrm{X}$ & & $\mathrm{X}$ & $\mathrm{X}$ & $\mathrm{X}$ & & $\mathrm{X}$ & & & $\mathrm{X}$ & - & Avusturya \\
\hline Virginia (2009) & & & & & & & & $\mathrm{X}$ & $\mathrm{X}$ & & & & $\mathrm{X}$ & - & ABD \\
\hline $\begin{array}{l}\text { Saskatoon } \\
(2010)\end{array}$ & $\mathrm{X}$ & & & $\mathrm{X}$ & & $\mathrm{X}$ & $\mathrm{X}$ & $\mathrm{X}$ & & & & & & - & Kanada \\
\hline
\end{tabular}

